\title{
Growth Differentiation Factor 5-Mediated Enhancement of Chondrocyte Phenotype Is Inhibited by Heparin: Implications for the Use of Heparin in the Clinic and in Tissue Engineering Applications
}

Bethanie I. Ayerst, BSc, MSc, PhD, ${ }^{1,2}$ Raymond A.A. Smith, BSc, MRes, PhD, Victor Nurcombe, BSc, PhD, Anthony J. Day, MA, DPhil, Catherine L.R. Merry, BSc, PhD,,4 and Simon M. Cool, BSc, PhD ${ }^{1,5}$

The highly sulfated glycosaminoglycan (GAG) heparin is widely used in the clinic as an anticoagulant, and researchers are now using it to enhance stem cell expansion/differentiation protocols, as well as to improve the delivery of growth factors for tissue engineering (TE) strategies. Growth differentiation factor 5 (GDF5) belongs to the bone morphogenetic protein family of proteins and is vital for skeletal formation; however, its interaction with heparin and heparan sulfate (HS) has not been studied. We identify GDF5 as a novel heparin/HS binding protein and show that HS proteoglycans are vital in localizing GDF5 to the cell surface. Clinically relevant doses of heparin $(\geq 10 \mathrm{nM})$, but not equivalent concentrations of HS, were found to inhibit GDF5's biological activity in both human mesenchymal stem/stromal cell-derived chondrocyte pellet cultures and the skeletal cell line ATDC5. We also found that heparin inhibited both GDF5 binding to cell surface HS and GDF5-induced induction of Smad 1/5/8 signaling. Furthermore, GDF5 significantly increased aggrecan gene expression in chondrocyte pellet cultures, without affecting collagen type X expression, making it a promising target for the TE of articular cartilage. Importantly, this study may explain the variable (and disappointing) results seen with heparin-loaded biomaterials for skeletal TE and the adverse skeletal effects reported in the clinic following long-term heparin treatment. Our results caution the use of heparin in the clinic and in TE applications, and prompt the transition to using more specific GAGs (e.g., HS derivatives), with better-defined structures and fewer off-target effects.

Keywords: cartilage, growth differentiation factor 5, heparan sulfate, heparin, mesenchymal stem cells, tissue engineering

\section{Introduction}

$\mathbf{H}$ EPARIN AND HEPARAN SULFATE (HS) are closely related glycosaminoglycans (GAGs) composed of repeating disaccharides of $N$-acetyl glucosamine and uronic acid. These sugar units can then undergo a series of modifications, including sulfation, deacetylation, and epimerization, to produce unique and complex derivatives, able to carry out a myriad of different functions. ${ }^{1}$ HS is produced by virtually all cells in the body, and contains highly modified/sulfated domains as well as regions devoid of sulfate groups. In contrast, heparin is made solely by connective tissue-type mast cells and can be seen as a hypersulfated variant of HS, with virtually continuous sulfation along its chains. ${ }^{2}$ In addition, one third of the chains found in unfractionated heparin have a unique pentasaccharide with 3-O sulfation (i.e.,

\footnotetext{
${ }^{1}$ Institute of Medical Biology, Agency for Science, Technology and Research (A*STAR), Singapore, Singapore.

${ }^{2}$ Wellcome Trust Centre for Cell-Matrix Research, Division of Cell Matrix Biology and Regenerative Medicine, School of Biology, Faculty of Biology Medicine and Health, Manchester Academic Health Science Centre, University of Manchester, Manchester, United Kingdom.

${ }^{3}$ School of Materials, University of Manchester, Manchester, United Kingdom.

${ }^{4}$ Wolfson Centre for Stem Cells, Tissue Engineering and Modelling, Centre for Biomolecular Sciences, University of Nottingham, Nottingham, United Kingdom.

${ }^{5}$ Department of Orthopaedic Surgery, Yong Loo Lin School of Medicine, National University of Singapore, Singapore, Singapore.

(C) Bethanie I. Ayerst et al. 2017; Published by Mary Ann Liebert, Inc. This Open Access article is distributed under the terms of the Creative Commons Attribution Noncommercial License (http://creativecommons.org/licenses/by-nc/4.0/) which permits any noncommercial use, distribution, and reproduction in any medium, provided the original author(s) and the source are credited.
} 
only present in $1-10 \%$ of HS chains), allowing it to bind to antithrombin III with high affinity. ${ }^{3}$ This property of heparin means that it has been widely used in the clinic as an anticoagulant for over 80 years, enabling dialysis and surgery, and helping to treat pathological conditions such as thrombosis and embolism. ${ }^{4}$

The low cost, easy availability, and status of heparin as an FDA- and EMA-approved product have prompted researchers to harness its properties for other applications. The high level of sulfation (and thus negative charge) carried by heparin means that it is able to bind, stabilize, and modulate the activity of a wide range of proteins, extending its therapeutic potential far beyond that of solely an anticoagulant. ${ }^{5}$ For example, a number of groups have begun using heparin to improve the delivery of growth factors such as bone morphogenetic protein 2 (BMP2), vascular endothelial growth factor (VEGF), and fibroblast growth factor 2 (FGF2), for tissue engineering (TE)/regeneration strategies, ${ }^{6-10}$ as well as to enhance stem cell expansion and differentiation protocols. ${ }^{11-14}$

Gaining prominence is the use of heparin-loaded delivery vehicles for skeletal TE. With the aging population, the prevalence and economic burden associated with degenerative bone and cartilage defects (such as osteoporosis and osteoarthritis) are increasing rapidly ${ }^{15,16}$; and as of yet, there are no fully effective ways to treat these conditions, indicating that there is a clear clinical need for research into viable and novel alternatives (see reviews Ayerst et al., ${ }^{6}$ Amini et al. ${ }^{17}$ Dhinsa and Adesida ${ }^{18}$ ).

The bone morphogenetic family of proteins, as their name suggests, plays crucial roles in bone and cartilage formation/ homeostasis, ${ }^{19}$ but their therapeutic potential is limited due to burst release kinetics and rapid clearance from the injury site. $^{20}$ This means that supraphysiological doses of BMP are needed for an effective outcome, resulting in increased cost as well as safety concerns (e.g., increased cancer risk). ${ }^{21,22}$ As a result, the use of biomaterials decorated with heparin has been extensively studied both in vitro and in vivo, for their ability to reduce the dosing requirements and improve the therapeutic potential of BMPs, including BMP2., 23,24 Most of these studies have shown very promising results, with heparin-loaded biomaterials improving BMP2 delivery, release, and osteogenic potential. However, the long-term side effects have not been tested, and in some cases, the use of heparin-loaded biomaterials has proven ineffective in vivo. ${ }^{25}$ In addition, we have shown in a rat ectopic model that, while collagen sponges soaked with BMP2 and heparin did result in more bone formation compared to sponges soaked with BMP2 alone, the use of an HS variant, rather than heparin, improved bone formation even further. ${ }^{26} \mathrm{We}$ hypothesize that while heparin may enhance the retention/ activity of BMP2 (or other GFs) under certain conditions, its binding "promiscuity" means that it may also inhibit other factors that play a role in the repair process, leading to suboptimal or deleterious results.

In addition to the potential off-target effects from heparinincorporated biomaterials, the long-term use of heparin as an anticoagulant has also resulted in a number of adverse clinical effects being reported, including thrombocytopenia, vascular reactions, and osteoporosis. ${ }^{27-30} \mathrm{We}$ recently showed that heparin has donor-dependent effects on the stemness and multipotency of human mesenchymal stem/stromal cells (hMSCs), and alters a number of signaling pathways associ- ated with hMSC growth and differentiation. ${ }^{31}$ This raises a concern regarding the long-term use of heparin in the clinic and its suitability in TE, for example, of skeletal tissues and cells of the bone marrow compartment.

Growth differentiation factor 5 (GDF5), also known as BMP14 or cartilage-derived morphogenetic protein 1 (CDMP1), belongs to the BMP subfamily of the transforming growth factor beta (TGF $\beta$ ) superfamily. Like BMP2 (and many other BMPs), it is established as playing a critical role in skeletal development and homeostasis, being important for the formation of bone, cartilage, ligaments, and tendons. ${ }^{32-34}$ Its importance in skeletal formation was first highlighted in mice carrying the brachypodism (bp) mutation, which results in changes in the length and number of bones in the limbs, and was found to be the result of mutations in the GDF5 gene. ${ }^{35}$ Following on from this, loss of function mutations in the human GDF5 gene has also been shown to result in a number of chondrodysplasias such as Grebe and Hunter-Thompson syndromes, ${ }^{36}$ and a single-nucleotide polymorphism in the $5^{\prime}$ untranslated region ( $5^{\prime}$ UTR) of human GDF5 has also been linked to osteoarthritis susceptibility. ${ }^{37}$ In contrast, overexpression of GDF5 has been shown to enhance chondrogenesis, increase the length and width of bones, and lead to joint fusions. ${ }^{38,39}$

Despite the clear importance of GDF5 for bone and cartilage formation, its use for in vitro differentiation protocols is somewhat under-researched compared to other TGF $\beta$ superfamily members. Interestingly, it has been demonstrated in human articular chondrocytes that GDF5 reduced the expression of matrix metalloproteinase 13 (MMP13; a matrixdegrading enzyme) and collagen $\mathrm{X}$ (a marker of chondrocyte hypertrophy), but led to an increased expression of aggrecan and sox 9 (both markers associated with chondrogenesis and extracellular matrix [ECM] production). ${ }^{40}$

hMSCs offer a number of benefits over chondrocytes for cell-based cartilage repair, including their ease of expansion and immunomodulatory capabilities. ${ }^{6,41-44}$ However, as of yet, methods for differentiating hMSCs, which typically employ the use of TGF $\beta 1 / 3$, result in the production of cartilage with inferior mechanical properties and poor structural organization compared to the native tissue, and in the production of hypertrophic rather than hyaline tissue, indicating that further refinement of protocols is required. ${ }^{4,46}$ Recent studies indicate that GDF5 has the potential to be used to improve the formation of hyaline cartilage from hMSCs, ${ }^{47,48}$ however, information on whether the chondrogenic activity of GDF5 is affected by heparin/HS is lacking.

There is a general trend for heparin/HS to modulate the activity of TGF $\beta$ superfamily members, ${ }^{49-53}$ and a heparin binding site has been predicted for GDF5 based on molecular docking methods and structural bioinformatics. ${ }^{54}$ However, this prediction has not been tested empirically. It is also well known that heparin/HS modulates the activities of different proteins in specific ways. ${ }^{55,56}$ The distinct heparin binding sites predicted for different BMP members ${ }^{54}$ indicate that the specificity and functional significance of these interactions are likely to differ between BMP family members. Indeed, it has already been shown that, while TGF $\beta 1 / 2$ is able to bind to heparin and HS, TGF $\beta 3$ does not interact with these GAGs. ${ }^{51}$

Given the pivotal role of GDF5 in the early stages of chondrogenesis, we aimed to look further into the potential of using GDF5 as a therapeutic agent for improving the chondrogenic differentiation of hMSCs, concentrating on its 
potential to increase cartilage matrix production without inducing hypertrophy of chondrocytes. In addition, given the increasing inclusion of heparin in biomaterials for skeletal TE (along with the adverse skeletal effects being reported in the clinic following long-term heparin treatment), we also felt it was important to investigate the interaction between GDF5 and heparin/HS and determine the effect of these GAGs on the biological activity of GDF5.

\section{Materials and Methods}

\section{Cell culture}

hMSCs were isolated and expanded from human bone marrow mononuclear cells from three healthy male donors aged 20-25 years (Lonza) and characterized, as previously described. ${ }^{57,58}$ Passage 4 cells were used for all subsequent experiments. ATDC5 cells (obtained from American Type Culture Collection [ATCC]) were maintained in Dulbecco's modified Eagle's medium (DMEM):Ham's F12 (1:1) (ATCC) supplemented with $5 \%(\mathrm{w} / \mathrm{v})$ fetal calf serum (HyClone), $2 \mathrm{mM}$ L-glutamine (ATCC), and $100 \mathrm{U} / \mathrm{mL}$ penicillin-streptomycin (P/S; Sigma-Aldrich). Cells were maintained at $37^{\circ} \mathrm{C}$ in a humidified atmosphere containing $5 \% \mathrm{CO}_{2}$ and detached with $0.125 \%$ trypsin/versene (Gibco) solution unless otherwise stated.

\section{Chondrogenic pellet culture}

Pellet cultures were set up based on a previously developed method, ${ }^{45}$ with some modifications. hMSCs $\left(0.25 \times 10^{6}\right.$ cells $)$ were resuspended in $0.5 \mathrm{~mL}$ chondrogenic media (hMSC Chondro BulletKit; Lonza) containing specified treatments in $15 \mathrm{~mL}$ polypropylene tubes; recombinant human GDF5 (molecular weight [MW] $27 \mathrm{kDa}$ ) and TGF $\beta 1$ (MW $25 \mathrm{kDa}$ ) were from Peprotech (both reconstituted without carrier protein), porcine intestinal mucosa heparin (H3149) was from Sigma (average MW $17.5 \mathrm{kDa}$ ), and porcine mucosal HS was from Celsus Laboratories (average MW $15 \mathrm{kDa}$ ). Tubes were centrifuged $(300 \mathrm{~g}, 5 \mathrm{~min})$ to generate high-density pellets and lids were then loosened, and the pellets were cultured for 21 days at $37^{\circ} \mathrm{C}, 5 \% \mathrm{CO}_{2}$, with medium changes every 3 days.

\section{Quantitative reverse transcription polymerase chain reaction}

Total RNA was isolated from chondrogenic pellet cultures using TRIzol ${ }^{\circledR}$ reagent (Life Technologies) according to the manufacturer's protocol and quantified using ultraviolet (UV) spectrophotometry on a NanoDrop 1000. Reverse transcription was carried out on $1 \mu \mathrm{g}$ RNA using the SuperScript ${ }^{\circledR}$ VILO $^{\mathrm{TM}}$ cDNA synthesis kit (Life Technologies) according to the manufacturer's instructions, but extending the incubation at $42^{\circ} \mathrm{C}$ to $2 \mathrm{~h}$. Each quantitative polymerase chain reaction (qPCR) was performed using $40 \mathrm{ng}$ complementary DNA (cDNA) and TaqMan Gene Expression assays for aggrecan (ACAN Hs00153936_ml), collagen X (COL10A1 Hs00166657_ml), and sex-determining region Y-box 9 (SOX9 Hs00165814_ml) from Life Technologies. Thermal cycling conditions of $95^{\circ} \mathrm{C}$ for $20 \mathrm{~s}$, followed by 45 cycles of $95^{\circ} \mathrm{C}$ for $1 \mathrm{~s}$ and $60^{\circ} \mathrm{C}$ for $20 \mathrm{~s}$ were used on the QuantStudio ${ }^{\mathrm{TM}} 6$ Flex Real Time PCR system (Life Technologies). Ct values were normalized to succinate dehydrogenase complex subunit A (SDHA) and results were plotted as relative expression units using the $2^{-\Delta \Delta \mathrm{Ct}}$ method.

\section{Surface plasmon resonance}

Surface plasmon resonance (SPR) was carried out as previously described. ${ }^{50,59}$ Briefly, $\sim 40$ response units (RUs) of biotinylated heparin was immobilized on a streptavidin chip using a Biacore T100 SPR instrument, with the HBS-EP running buffer (10 mM HEPES, $150 \mathrm{mM} \mathrm{NaCl}, 3.0 \mathrm{mM}$ EDTA, $0.05 \%$ [v/v] Tween 20, pH7.4) and following the manufacturer's immobilization protocol (GE Healthcare). A low quantity of heparin was immobilized to facilitate the measurement of protein binding and reduce mass transport limitations. ${ }^{50,60-63}$

The interaction of GDF5 with immobilized heparin was investigated by injecting a range of GDF5 concentrations (serial twofold dilution; from 100 to $12.5 \mathrm{nM}$ ) diluted in the HBS-EP-0.1 running buffer (i.e., containing $0.1 \%[\mathrm{v} / \mathrm{v}]$ Tween 20) over the heparin-coated chip at a flow rate of $30 \mu \mathrm{L} / \mathrm{min}$ for $2 \mathrm{~min}$, followed by washing with the HBSEP-0.1 running buffer for $10 \mathrm{~min}$. The chip was regenerated with two $1 \mathrm{~min}$ washes of $2 \mathrm{M} \mathrm{NaCl}$ at $30 \mu \mathrm{L} / \mathrm{min}$ after each sample. The sensograms generated by the instrument were automatically adjusted by subtracting the responses from the control cell of the same chip, to represent specific binding. Kinetic values were obtained by fitting the SPR curves to the 1:1 Langmuir binding model using the BIAevaluation software. The $\mathrm{R}_{\max }$ was fitted locally (i.e., for each concentration) in all curve fits. ${ }^{64}$ Mean affinity and kinetic values ( \pm standard error of the mean [SEM]) were derived from two separate experiments. The $\chi^{2}$ value indicates the mean square of the signal noise and provides a statistical measure of the closeness of fit (BIAevaluation Handbook).

Competitive binding experiments were carried out using SPR as above, but where $100 \mathrm{nM}$ GDF5 in HBS-EP-0.1 was mixed with 0,100 , or $1000 \mathrm{nM}$ of heparin, HS, or purified HS fractions before being injected over the heparin-coated chip. For each GAG condition, the maximum binding response was normalized to the response obtained from GDF5 alone, where all analyses were repeated twice. Before these experiments, the porcine mucosal HS was fractionated by ion-exchange chromatography on a HiTrap ${ }^{\mathrm{TM}}$ diethylaminoethyl (DEAE) sepharose column (GE Healthcare) equilibrated in $20 \mathrm{mM}$ phosphate, $150 \mathrm{mM} \mathrm{NaCl}$, pH 7.2, and with sequential elution in $350 \mathrm{mM} \mathrm{NaCl}$ (HS350), followed by $700 \mathrm{mM} \mathrm{NaCl}$ (HS700) in an equilibrating buffer. The HS350 and HS700 fractions were desalted on a HiPrep 26/10 desalting column (GE Healthcare) before being used for SPR.

\section{Differential scanning fluorimetry}

Differential scanning fluorimetry (DSF) was carried out based on a previously reported protocol, with some modifications. ${ }^{65}$ Protein/GAG mixtures were prepared in standard polypropylene vials, adding the components in the following order: water (to take final volume to $32 \mu \mathrm{L}$ ), $0.1 \mathrm{M} \mathrm{NaAc}$, $0.15 \mathrm{M} \mathrm{NaCl}, \mathrm{pH} 5,4 \mathrm{M}$ Urea, $7.5 \mu \mathrm{M}$ GDF5, $80 \times \mathrm{SYPRO}$ dye, and $75 \mu \mathrm{M}$ GAG. Three aliquots of $10 \mu \mathrm{L}$ were then transferred to a 96-well plate for each sample and immediately read on the QuantStudio 6 Flex Real-Time PCR system (Life Technologies) with a 120 -s prewarming step at $31^{\circ} \mathrm{C}$ and a subsequent gradient between $32^{\circ} \mathrm{C}$ and $95^{\circ} \mathrm{C}$, in steps of $0.5^{\circ} \mathrm{C}$, each $20 \mathrm{~s}$ in duration. Data were collected using the TAMRA dye setting (excitation wavelength $560 \mathrm{~nm}$ and emission wavelength $582 \mathrm{~nm}$ ) and analyzed by applying an exponential correlation function approximation of the first derivative for 
each melting curve. The maxima were used to determine the mean melting temperature $\left(\mathrm{T}_{\mathrm{m}}\right)$ for each condition.

\section{Flow cytometry}

ATDC5 cells were detached with TrypLE ${ }^{\mathrm{TM}}$ (Life Technologies) and $2 \times 10^{5}$ cells were treated with the stated doses of heparinase I, II, and III (Iduron) in phosphate-buffered saline for $30 \mathrm{~min}$ at room temperature. Cells were washed and incubated with 50 nM GDF5 (for work in ATDC5 cells, recombinant carrier-free mouse GDF5 was purchased from R\&D Systems) for $30 \mathrm{~min}$ on ice, before being washed and labeled with 1:30 anti-GDF5 antibody (R\&D Systems) and 1:50 anti-HS 10E4 antibody (Amsbio), or the isotypematched controls for $30 \mathrm{~min}$ on ice. Cells were then washed and incubated with 1:500 donkey anti goat IgG-FITC antibody and 1:500 goat anti mouse IgM-Alexafluor 633 (Invitrogen) for $30 \mathrm{~min}$ on ice. Finally, cells were fixed in $1 \%$ (w/v) paraformaldehyde (PFA) and analysis was performed using the $\mathrm{BD}^{\mathrm{TM}}$ LSRII flow cytometer.

Data were analyzed using FlowJo7 software. The effect of unfractionated heparin/HS, selectively desulfated heparin derivatives, or size-fractionated derivatives of heparin (labeled by degree of polymerization [dp] equivalent to number of monosaccharides) (Iduron) on GDF5 binding to the cell surface was examined as above, without the heparinase treatment step, and incubating cells with the stated GDF5GAG concentrations; cells were stained with the anti-GDF5 antibody. For the size-fractionated heparin derivatives, the average MWs provided by Iduron were used. For the desulfated heparin derivatives, an average MW of $17.5 \mathrm{kDa}$ was used, and the removal of sulfates was then accounted for based on the average composition of heparin sulfation ${ }^{66}$ and the supplier's (Iduron) estimate on the percentage removal of each type of sulfation achieved during the desulfation process.

\section{Alkaline phosphatase assay}

The alkaline phosphatase (ALP) assay was performed as previously described. ${ }^{67}$ Briefly, ATDC5 cells were seeded at a density of $1 \times 10^{4}$ cells/well of a 96-well plate in maintenance media. After $24 \mathrm{~h}$, cells were starved for $5 \mathrm{~h}$ (DMEM:Ham's F12, 0.5\% FCS, 2 mM L-glutamine, $100 \mathrm{U} / \mathrm{mL}$ P/S). Cells were then stimulated with the stated doses of GDF5/GAG for 3 days. GAGs tested were heparin, HS, and BMP2 affinity-selected HS (termed HS3; see Murali et al. ${ }^{68}$ Rai et al. ${ }^{69}$ ). The ALP activity was measured in triplicate by lysing cells in the ALP buffer 1 $\left(0.1 \mathrm{M}\right.$ glycine, $1 \%$ [v/v] Nonidet P-40, $1 \mathrm{mM} \mathrm{MgCl}_{2}$, and $1 \mathrm{mM} \mathrm{ZnCl}_{2}, \mathrm{pH}$ 9.6) for $1 \mathrm{~h}$ at room temperature with gentle shaking, followed by the addition of one volume of ALP buffer 2 (5 mM $p$-nitrophenyl phosphate [ $p$-NPP], $0.1 \mathrm{M}$ glycine, $1 \mathrm{mM} \mathrm{MgCl}_{2}$, and $1 \mathrm{mM} \mathrm{ZnCl}_{2}, \mathrm{pH}$ 9.6). The amount of $p-\mathrm{NP}$ released from the $p$-NPP substrate was measured spectrophotometrically at $405 \mathrm{~nm}$, and the ALP activity was calculated relative to control or GDF5-only treatment.

\section{Cell signaling}

ATDC5 were seeded in maintenance media at a density of $1 \times 10^{4}$ cells $/ \mathrm{cm}^{2}$ and cultured for $36 \mathrm{~h}$. Cells were then starved overnight (DMEM:Ham's F12, $100 \mathrm{U} / \mathrm{mL}$ P/S) before being treated with the stated doses of GDF5/GAG for $1 \mathrm{~h}$. Cells were then lysed in $2 \times$ Laemmli buffer (Sigma-Aldrich) and resolved on a 4-12\% (w/v) gradient sodium dodecyl sulfatepolyacrylamide gel electrophoresis (SDS-PAGE) gel (Life Technologies), followed by electrotransfer onto a nitrocellulose membrane (Millipore). Blots were incubated with antibodies against SMAD1/5/8 (1:500; Santa-Cruz; sc-6031-R, rabbit polyclonal IgG; reacts with mouse, rat, and human), phosphorylated SMAD 1/5/8 (1:1000; now known as SMAD1/ 5/9; Cell Signaling; 13820P, rabbit monoclonal; reacts with mouse, rat, and human), actin (1:5000; Millipore; MAB1501, mouse monoclonal; reacts with all vertebrates), and GDF5 (1:2000; R\&D Systems; AF853, goat polyclonal IgG; reacts with mouse), followed by the appropriate horseradish peroxidase (HRP)-conjugated secondary antibodies (Jackson ImmunoResearch). LumiGLO ${ }^{\circledR}$ Chemiluminescent Substrate Kit (Kirkegaard \& Perry Laboratories) was used to visualize immunoreactive bands on the C-DiGit ${ }^{\circledR}$ Blot Scanner (LI-COR). Densitometry was carried out using Image Studio Light Version 4.0 software. Semiquantitative analyses of immunoblots were obtained by normalizing phosphorylated Smad 1/5/8 levels to total Smad 1/5/8 levels. Actin is shown as a visual control, but was not used in densitometry measurements.

\section{Statistical analysis}

All data are displayed as mean \pm SEM. Results were analyzed using one-, two-, or three-way analysis of variance (ANOVA), with Tukey post hoc testing where appropriate. Goodness of fit linear regression analysis was used to determine the correlation between endogenous HS and GDF5 bound to the cell surface. Semilog nonlinear regression analysis was used to determine the correlation between the dosing of exogenous GAG fractions and the amount of GDF5 that bound to the cell surface. Significance was set at $p$-value $\leq 0.05$. All results were analyzed with GraphPad Prism software version 6, except three-way ANOVA, which was analyzed using IBM SPSS Statistics version 21.

\section{Results}

\section{Differential effects of GDF5 and TGF $\beta 1$ on the chondrogenic differentiation of hMSCs}

GDF5 and TGF $\beta 1$ have both been identified as key regulators of chondrogenesis. However, while TGF $\beta 1$ is routinely used as a supplement to improve the chondrogenic differentiation of hMSCs, there is less information available for GDF5. We found that hMSC-derived chondrocyte pellets stimulated with TGF $\beta 1$ for 21 days resulted in no change in aggrecan expression compared to control, irrespective of dose (Fig. 1A). In agreement with published studies, ${ }^{45,46,70}$ TGF $\beta 1$ significantly increased the expression of collagen $\mathrm{X}$ and sox 9 (Fig. 1C, E). Notably, the lowest tested dose of $10 \mathrm{ng} / \mathrm{mL}$ generated the greatest effect for collagen X expression (78-fold increase, $p<0.0001$ ), and increasing the dose of TGF $\beta 1$ from 10 to $150 \mathrm{ng} / \mathrm{mL}$ had no additional effect on sox 9 expression (an approximately twofold increase for both doses, $p<0.0001$ ). In contrast to TGF $\beta 1$, stimulation with GDF5 for 21 days significantly increased both aggrecan and sox 9 expression, but interestingly had no effect on collagen X levels, irrespective of dose (Fig. 1A-C). Post hoc analysis demonstrated that aggrecan and sox9 levels were significantly increased at doses $\geq 75 \mathrm{ng} / \mathrm{mL}$, with the greatest effect being seen at the highest 

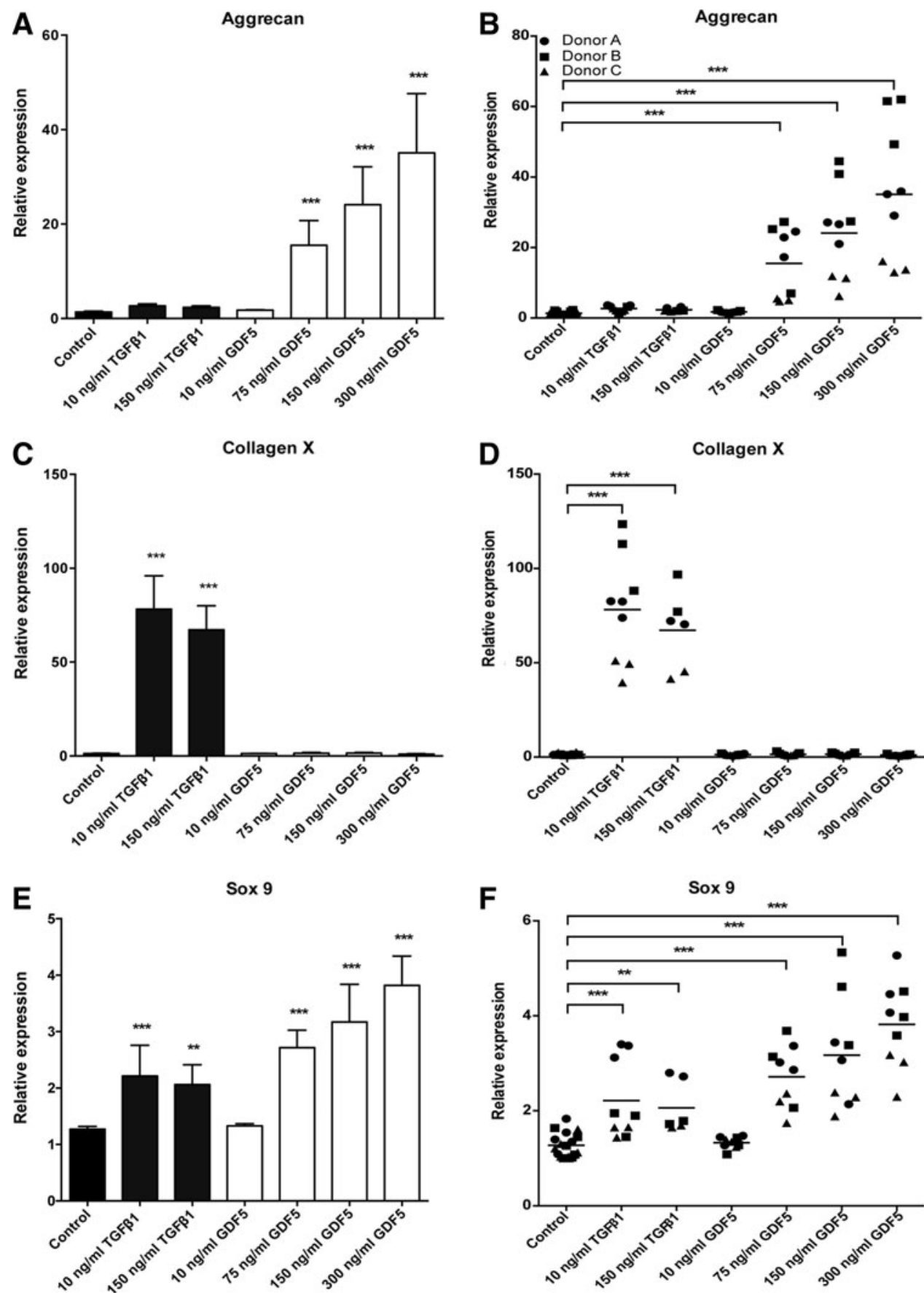

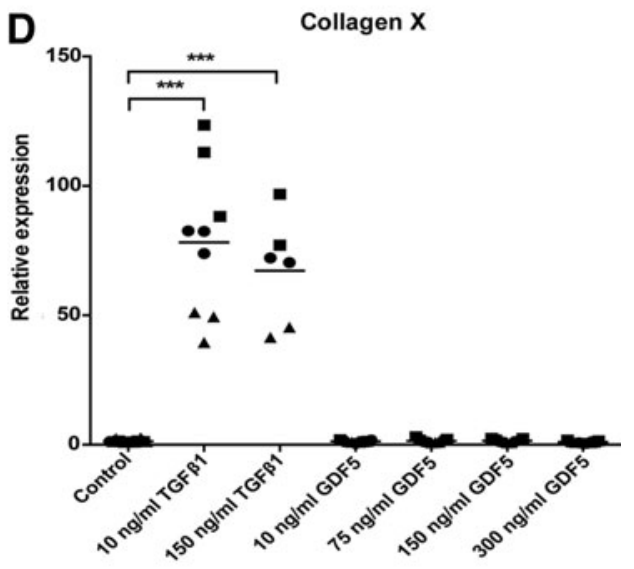

$\mathbf{F}$

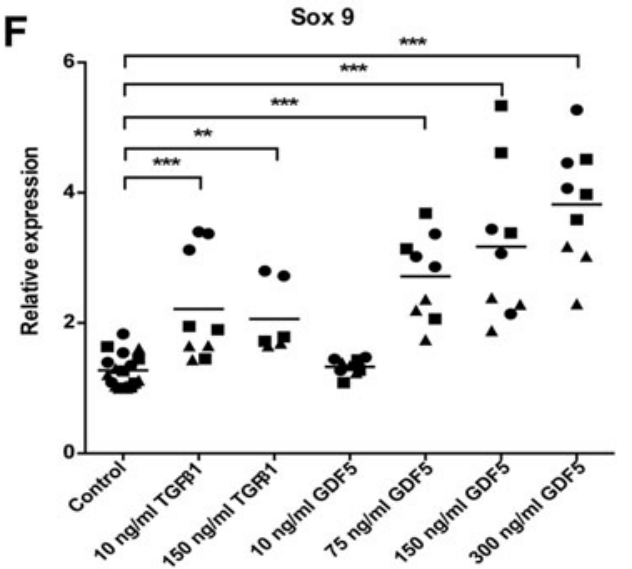

FIG. 1. Differential effects of GDF5 and TGF $\beta 1$ on the chondrogenic differentiation of hMSCs. hMSCs were cultured as chondrogenic pellet cultures for 21 days with TGFß1 $(10-150 \mathrm{ng} / \mathrm{mL}=0.4$ $6 \mathrm{nM}$; dark grey bars) or GDF5 (10-300 ng/mL $=0.4$ $11.1 \mathrm{nM}$; white bars) and the levels of mRNA transcripts for aggrecan $(A, B)$, collagen $X(\mathbf{C}, \mathbf{D})$, and sox $9(\mathbf{E}, \mathbf{F})$ analyzed by qPCR. (A, C, E) Data are presented as mean \pm SEM from three separate hMSC donors, with triplicate experiments performed for each donor $(n=9)$. $(\mathbf{B}, \mathbf{D}, \mathbf{F})$ All replicates for each donor tested are shown (horizontal lines show mean). $* p<0.05$, $* * p<0.01, * * * p<0.001$. Treatment data are compared to control pellets. GDF5, growth differentiation factor 5; hMSCs, human mesenchymal stem/stromal cells; mRNA, messenger RNA; qPCR, quantitative polymerase chain reaction; SEM, standard error of the mean; TGF $\beta 1$, transforming growth factor beta 1 . dose tested; that is, at $300 \mathrm{ng} / \mathrm{mL}$, there was a 35 -fold increase in aggrecan $(p<0.0001)$ and a 3.8 -fold increase in sox9 $(p<0.0001)$ expression. Importantly, although there was a significant donor-to-donor variability $(p<0.0001)$, all donors showed the same pattern of response to either GDF5 or TGF $\beta 1$ stimulation, although to varying extents (Fig. 1B, D, F).

To more fully understand the temporal changes in gene expression, we assessed messenger RNA (mRNA) transcript levels at days 3, 7, 14, and 21 (Fig. 2). As reported above for the 21-day time point, simulation with TGF $\beta 1(10 \mathrm{ng} / \mathrm{mL})$ for 3, 7, or 14 days had no effect on aggrecan expression (Fig. 2A). However, stimulation with TGF $\beta 1$ significantly increased the expression of both collagen $X$ and sox 9 (Fig. 2C, E). This increase in expression was seen on day 14 for both collagen $\mathrm{X}$ (121-fold increase, $p<0.0001)$ and sox9 (1.6-fold increase, $p<0.05)$, and the expression was then maintained up to day 21 . In contrast, stimulation with GDF5 $(150 \mathrm{ng} / \mathrm{mL})$ at time points earlier than 21 days had no significant effect on either aggrecan or sox 9 expression (Fig. 2A, E). However, in the case of aggrecan, there was a substantial increase in gene expression on day 14 in some donors (4.3-fold increase for donor A, $p<0.001$, and 18.8-fold increase for donor C, $p<0.001)$ and the lack of overall significance was instead due to donor variability, where donor B took longer to respond (to increase aggrecan expression), and so appears unresponsive on day 14 (Fig. 2B). Notably, stimulation with GDF5 did not induce collagen $X$ expression, irrespective of time (Fig. 2C). When hMSC chondrogenic pellets were stimulated with a 

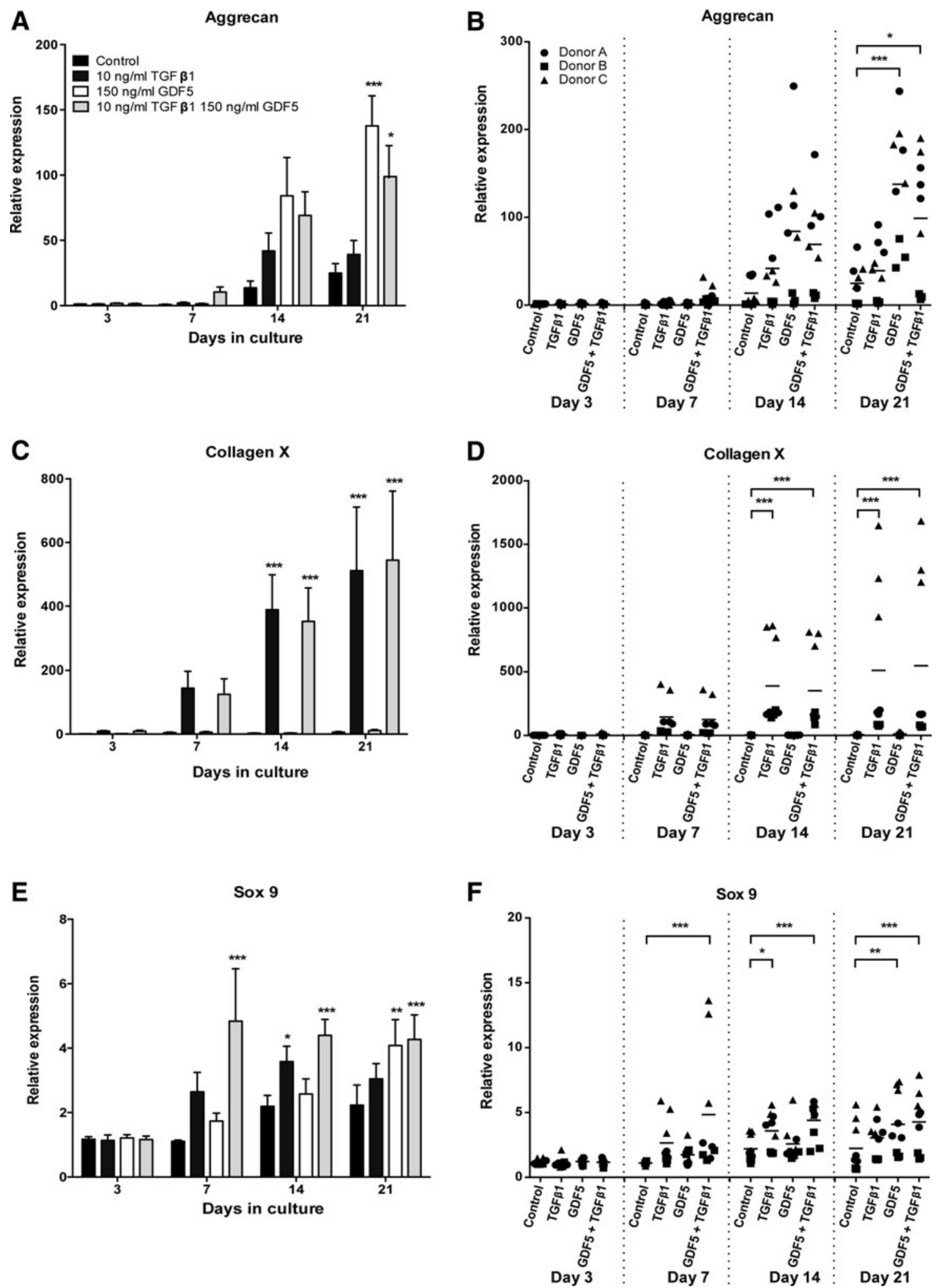

FIG. 2. Temporal effects of GDF5 and TGF $\beta 1$ on the chondrogenic differentiation of hMSCs. hMSCs were cultured as chondrogenic pellet cultures for up to 21 days with effective doses of TGF $\beta 1$ ( $10 \mathrm{ng} / \mathrm{mL}=0.4 \mathrm{nM}$; dark grey bars), GDF5 $(150 \mathrm{ng} / \mathrm{mL}=5.6 \mathrm{nM}$; white bars $)$, or a combination of both $(\mathrm{TGF} \beta 1$ at $10 \mathrm{ng} / \mathrm{mL}$ and GDF5 at $150 \mathrm{ng} / \mathrm{mL} ;$ light grey bars $)$, and the levels of mRNA transcripts for aggrecan $(\mathbf{A}, \mathbf{B})$, collagen X $(\mathbf{C}, \mathbf{D})$, and sox 9 (E, F) analyzed by qPCR. (A, C, E) Data are presented as mean \pm SEM from three separate hMSC donors, with triplicate experiments performed for each donor $(n=9)$. (B, D, F) All replicates for each donor tested are shown (horizontal lines show mean). * $p<0.05, * * p<0.01$, $* * * p<0.001$. Treatment data are compared to control pellets for the same time point analyzed. 
combination of TGF $\beta 1$ and GDF5, the expression of aggrecan, collagen $X$, and sox 9 was all significantly increased (Fig. 2A, C, E). Similar to GDF5 treatment alone, a significant increase in aggrecan expression was only seen by day 21 of culture (fourfold increase, $p<0.05$ ), while an increase in collagen $\mathrm{X}$ expression mirrored that of TGF $\beta 1$ treatment alone, with an increase in expression being seen on day 14 (90-fold increase, $p<0.0001$ ) and maintained up to day 21 . In comparison to treatment with either GDF5 or TGF $\beta 1$ alone, the combination of both GFs led to an earlier increased expression of sox 9, which was seen on day 7 (4.4-fold increase, $p<0.0001)$ and maintained up to day 21. Again, although there was significant donor-to-donor variability (collagen $\mathrm{X}, p<0.0001$; sox 9, $p<0.0001$; aggrecan, $p<0.005$ ) (Fig. $2 \mathrm{~B}, \mathrm{D}, \mathrm{F}$ ), the three donors tested all shared the same pattern of responses.

\section{GDF5 is a heparin/HS binding protein}

Although a heparin binding sequence has been predicted for GDF5 $^{54}$ and GAGs have been demonstrated to potentiate the activity of other TGF $\beta$ family members, ${ }^{26,50,51,68}$ there is currently no direct evidence that GDF5 is a heparin binding
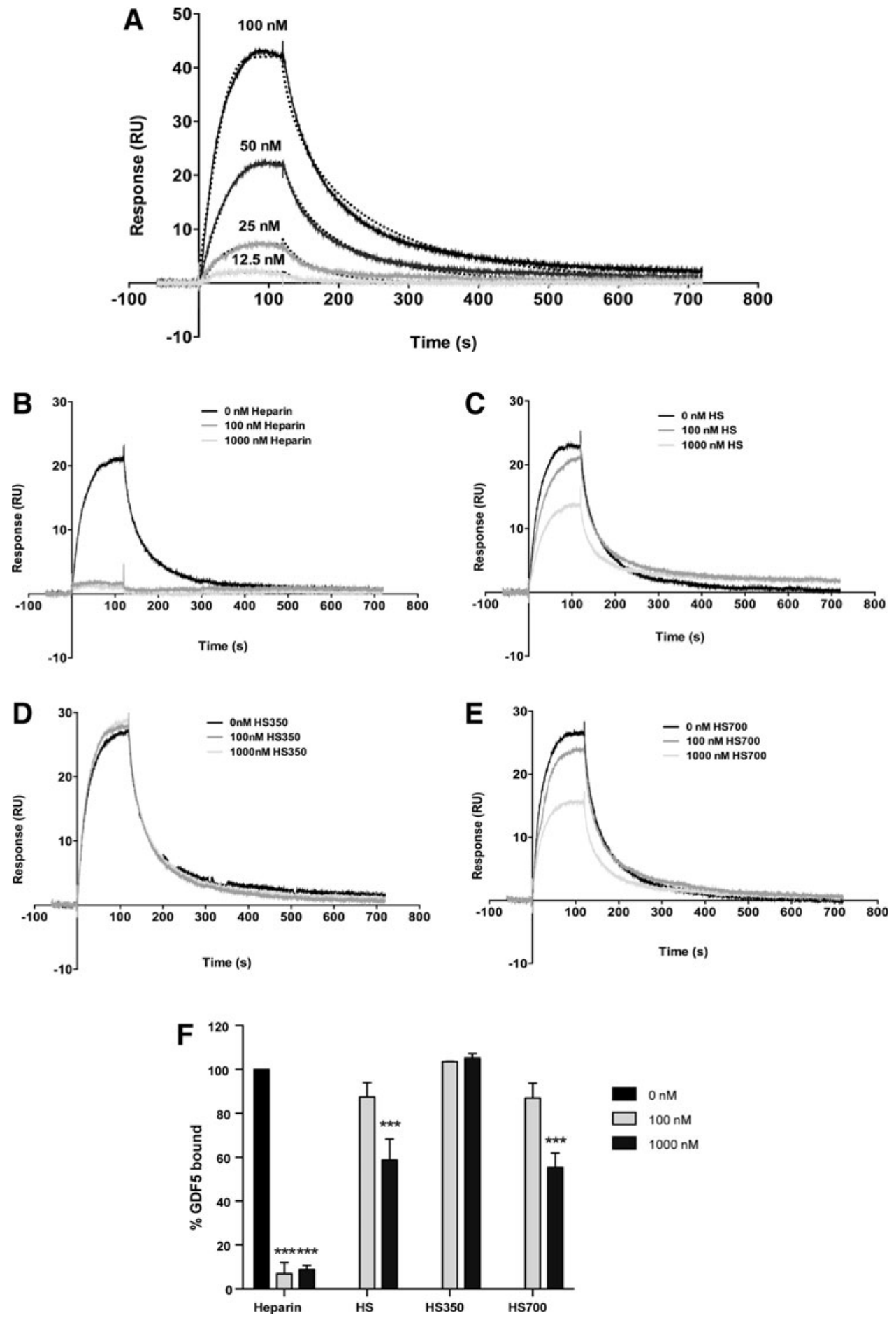

FIG. 3. GDF5 is a heparin/ HS binding protein. SPR was used to determine the change in binding response to increasing concentrations of GDF5 (serial dilution of 12.5-100 nM) injected over a heparin-coated $(\sim 40$ RU) streptavidin chip (dotted lines show fits with the Langmuir 1:1 model, which were used for calculating the $K_{D}$ values reported in the text) (A). To compare the affinities of different GAG species for GDF5 binding, SPR competition assays were carried out. GDF5 was preincubated with 0,100 , or $1000 \mathrm{nM}$ of heparin (B), HS (C), HS350 (D), or HS700 (E) before being injected over the heparin-coated streptavidin chip. To determine changes in GDF5 binding in the presence of GAGs, data were normalized to GDF5 treatment alone $(0 \mathrm{nM}$ GAG) (F). (A-E) Representative sensograms of two independent experiments, results shown in $(\mathbf{F})$ are mean \pm SEM. $* * * p<0.001$ relative to $0 \mathrm{nM} \mathrm{GAG}$ control. GAG, glycosaminoglycan; HS, heparan sulfate; RU, response unit; SPR, surface plasmon resonance. 
protein. We therefore investigated the ability of GDF5 to bind heparin/HS by SPR. Biotinylated heparin was immobilized on a streptavidin chip, and increasing concentrations of GDF5 flowed over the chip surface. GDF5 binding increased in a dose-dependent manner on to the heparin-coated surface (Fig. 3A). Using the BIAevaluation software and upon visual inspection, the interaction between heparin and GDF5 was best fitted to the 1:1 Langmuir model (Fig. 3A), that is, providing better fits compared to the bivalent analyte or two-state reaction models. Using 1:1 fitting (with $\mathrm{R}_{\max }$ as a local rather than global parameter), the association and dissociation rate constants were $2.3 \pm 0.7 \times 10^{5} \mathrm{M}^{-1} \mathrm{~s}^{-1}$ and $9.8 \pm 0.7 \times 10^{-3} \mathrm{~s}^{-1}$, respectively (based on values averaged from two separate experiments). The corresponding affinity constant $K_{\mathrm{D}}$ was found to be $49.6 \pm 19.4 \mathrm{nM}\left(\chi^{2} 4.5 \pm 0.2\right)$, indicating that GDF5 binds to heparin with high affinity.

The relative affinities of heparin and HS for GDF5 binding were also assessed using SPR competition assays. While GDF5 preincubated with heparin competitively inhibited GDF5 binding to the heparin-coated chip by $>90 \%(p<$ $0.0001)$ at both concentrations tested (100 and $1000 \mathrm{nM}$ tested) (Fig. 3B, F), unfractionated HS only significantly inhibited GDF5 binding at the higher concentration tested of $1000 \mathrm{nM}$ (41\% reduction in binding, $p<0.0001)$ (Fig. 3C, F). In addition, the HS350 fraction (eluted from an ion-exchange resin at low salt) was unable to competitively inhibit GDF5 binding to the heparin-coated chip (Fig. 3D, F); HS700, eluted in high salt, was similar to the HS starting material, significantly inhibiting binding at the higher dose of $1000 \mathrm{nM}(45 \%$ inhibition, $p<0.0001$ ) (Fig. 3E, F). This indicates that GDF5 has a significantly higher affinity for heparin than HS and sulfation levels play an important role in the interaction.

In addition to the SPR data, and as a confirmatory experiment, we next sought to look at the GDF5-heparin/-HS interaction in solution phase, using a method previously applied to FGF-heparin interactions. ${ }^{65}$ Sypro $^{\mathrm{TM}}$ Orange fluorescent dye has a specific affinity for hydrophobic surfaces that become exposed as proteins unfold; evidence of thermostabilization in the presence of heparin or HS would be indicative of a biological interaction. In the presence of either heparin or HS,
GDF5 displayed altered melt curve profiles (Fig. 4A) and significantly higher melting $\mathrm{T}_{\mathrm{m}}$ values $\left(\mathrm{GDF} 5\right.$ alone $=65.6^{\circ} \mathrm{C}$; $\mathrm{GDF} 5+$ heparin $=71.6^{\circ} \mathrm{C}, \quad p<0.0001 ; \quad \mathrm{GDF} 5+\mathrm{HS}=69.6^{\circ} \mathrm{C}$, $p<0.0001$ ), providing further evidence that GDF5 interacts with these GAGs (Fig. 4B); which is consistent with the SPR data for heparin and HS. Dose-dependent stabilization would provide additional data to support this conclusion. ${ }^{71}$

\section{Heparin, but not equivalent doses of HS, inhibits GDF5-induced chondrogenic differentiation of hMSCs}

Given the important role of GDF5 in bone and cartilage formation and the interaction between GDF5 and heparin/HS demonstrated above, we next sought to investigate the effects of these GAGs on GDF5-induced biological activity. hMSCderived chondrogenic pellets were cultured for 21 days with a suboptimal dose of $75 \mathrm{ng} / \mathrm{mL}$ GDF5 in the presence of increasing doses of GAG $(1-10,000 \mathrm{nM})$, and the effects of these GAGs on GDF5-induced aggrecan mRNA expression were evaluated (Fig. 5A). Clinically relevant doses $(\geq 10 \mathrm{nM})$ of heparin were found to inhibit GDF5-induced chondrogenic activity, with $100 \mathrm{nM}(1.75 \mu \mathrm{g} / \mathrm{mL})$ heparin decreasing aggrecan expression by 4.2 -fold $(p<0.0001)$ compared to GDF5 treatment alone. In comparison, HS only inhibited GDF5induced aggrecan expression at the highest dose tested of $10,000 \mathrm{nM}$ (3.5-fold at $150 \mu \mathrm{g} / \mathrm{mL} ; p<0.01)$. Treatment of chondrogenic pellets with GAG alone also had no effect on aggrecan expression compared to control pellets. The pattern of results was similar for all three hMSC donors tested, although donor-to-donor variability was again seen $(p<0.0001)$ (Fig. 5B, C).

\section{Heparin, but not HS, inhibits GDF5-induced osteogenic differentiation of skeletal ATDC5 cells}

To further characterize the interaction of GAGs with GDF5, we moved to a well-established assay system using the skeletal ATDC5 cell line, ${ }^{67,72}$ where emergence of ALP activity is used to indicate differentiation. ${ }^{73,74}$ Both BMP2 and GDF5 significantly increased the ALP activity (Fig. 6A, B).
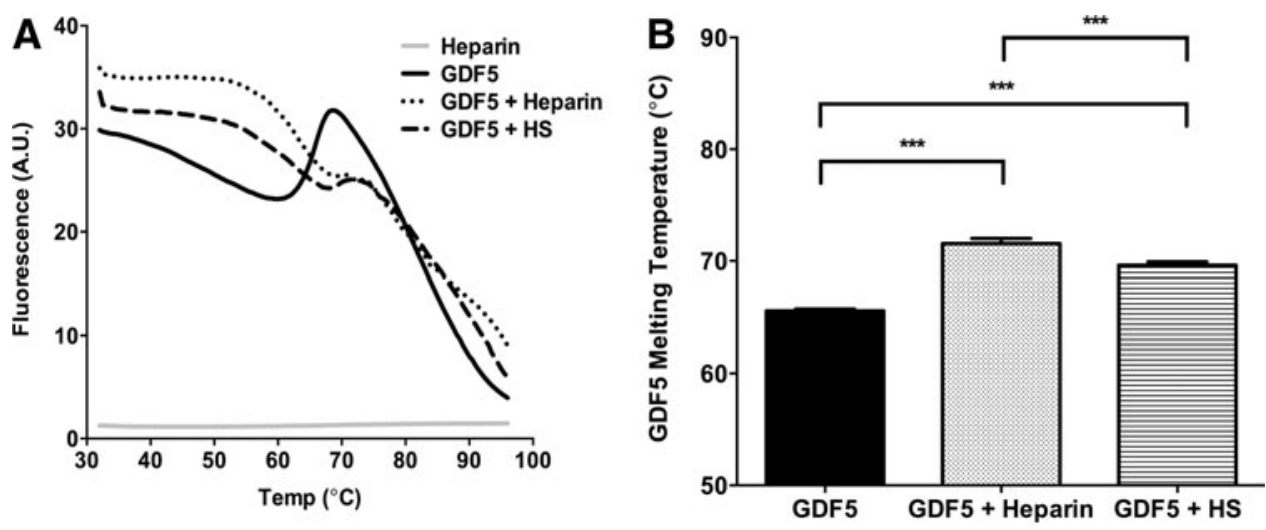

FIG. 4. Heparin/HS stabilizes GDF5. DSF was used to analyze the interaction between GDF5 and heparin/HS in solution phase. GDF5 alone or in the presence of GAG was mixed with Sypro ${ }^{\mathrm{TM}}$ Orange dye, and subjected to a temperature gradient from $32^{\circ} \mathrm{C}$ to $95^{\circ} \mathrm{C}$ in steps of $0.5^{\circ} \mathrm{C}$, each of $20 \mathrm{~s}$ duration (in a PCR machine) (A, B). Changes in fluorescence intensity as the protein unfolded was recorded by the PCR machine and used to plot the melt curves (A). The first derivatives of the melting curves were also plotted and used to identify the maxima (melting temperature) from each melt curve (B). (A) Representative profile from three independent experiments (where each DSF experiment was carried out in triplicate); results shown in $(\mathbf{B})$ are mean \pm SEM. $* * * p<0.001$. DSF, differential scanning fluorimetry. 

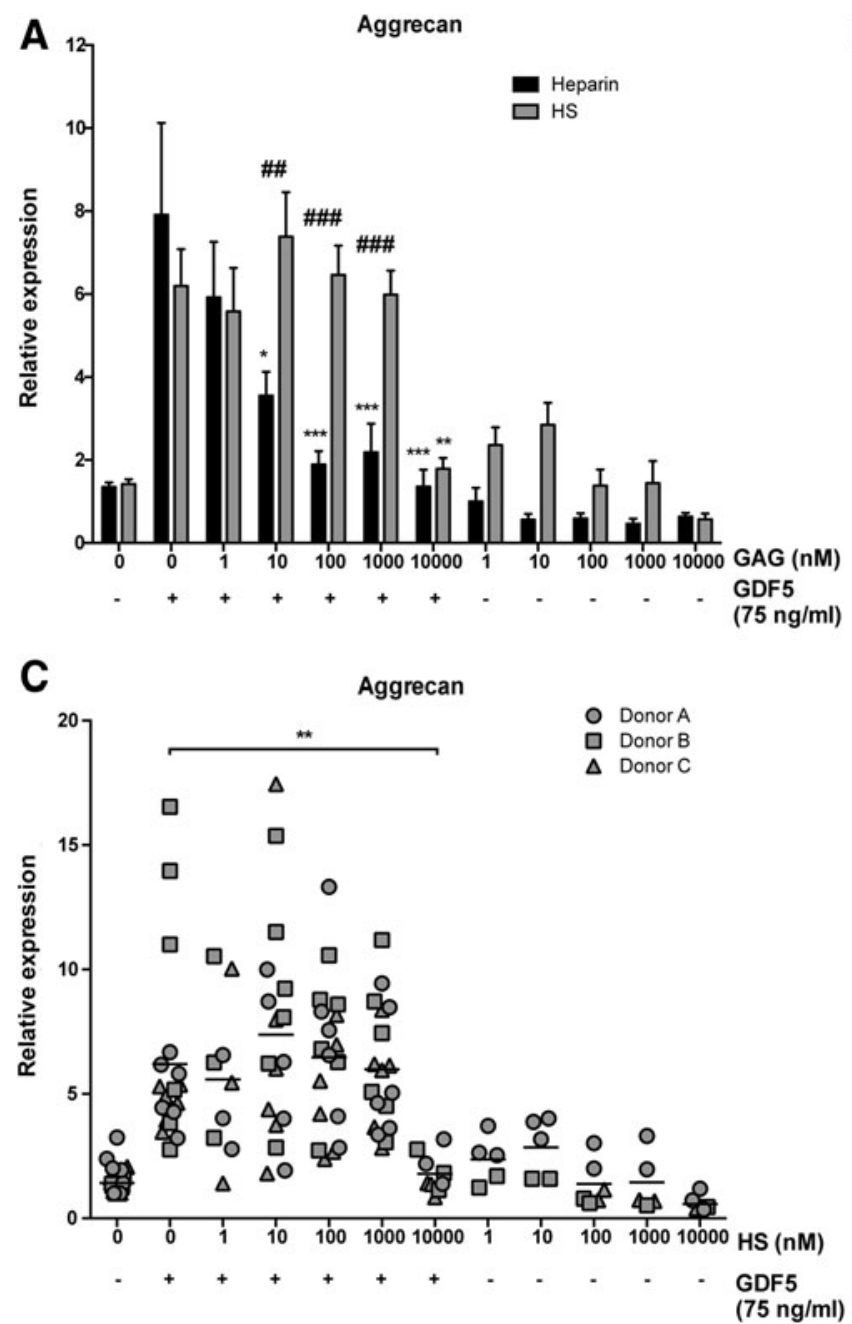

Post hoc testing for GDF5 indicated this effect was only significant at doses $\geq 25 \mathrm{nM}(p<0.0001)$, while for BMP2, significance was seen at the lowest dose tested of $\geq 5 \mathrm{nM}$ $(p<0.0001)$. We then proceeded to look at the dose-dependent effect of heparin, HS, and HS3 (a purified HS fraction known to increase BMP2 bioactivity ${ }^{68,69}$ ) on GDF5-/BMP2-induced ALP production, using the lowest growth factor concentration that gave a significant increase in ALP (Fig. 6C, D). Similar to our observations for hMSCs, heparin inhibited the GDF5-induced ALP activity $(p<0.0001)$, while HS had no effect (Fig. 6C). Post hoc analysis demonstrated that doses $\geq 100 \mathrm{nM}$ heparin were able to significantly inhibit the GDF5induced activity, with a $20 \%$ reduction in ALP $(p<0.0001)$ seen at this dose. HS3 significantly enhanced the GDF5induced ALP activity at doses of $10(p<0.0001)$ and $100 \mathrm{nM}$ ( $p<0.001)$, with $\sim 15 \%$ increase in activity, while higher doses of HS3 had no significant effect (Fig. 6C). In contrast to the results seen with GDF5, heparin $(p<0.001)$ and HS $(p<0.01)$ both significantly enhanced the BMP2-induced ALP activity (Fig. 6D). Heparin significantly enhanced the activity at doses of $100(p<0.01)$ and $1000 \mathrm{nM}(p<0.001)$, with a $27.6 \%$ increase in activity observed with $100 \mathrm{nM}$ heparin, while the lowest $(10 \mathrm{nM})$ and highest $(10,000 \mathrm{nM})$ dose had no significant effect. Notably, HS only significantly enhanced the BMP2-induced ALP activity at the highest dose tested $(10,000 \mathrm{nM}, p<0.001)$.

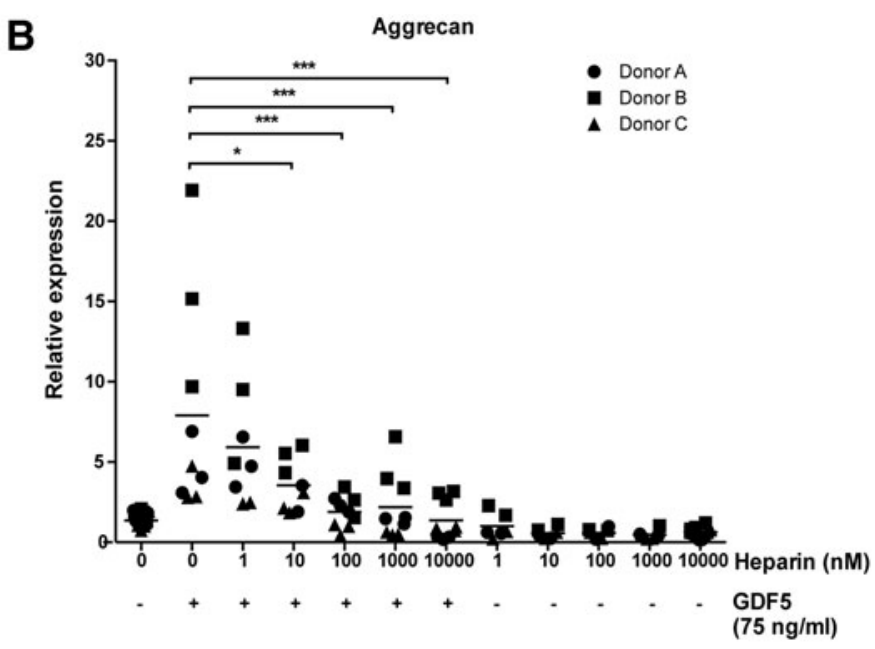

FIG. 5. Heparin, but not equivalent doses of HS, inhibits GDF5-induced chondrogenic differentiation of hMSCs. qPCR was used to evaluate the effect of GAGs on GDF5-induced aggrecan expression in hMSC-derived chondrogenic pellets. Pellets were treated for 21 days with $75 \mathrm{ng} / \mathrm{mL}$ ( $2.8 \mathrm{nM})$ GDF5 in the absence/presence of a range of heparin $(1-10,000 \mathrm{nM}=$ $17.5 \mathrm{ng} / \mathrm{mL}-175 \mu \mathrm{g} / \mathrm{mL})(\mathbf{A}, \mathbf{B})$ or HS $(1-10,000 \mathrm{nM}=15 \mathrm{ng} /$ $\mathrm{mL}-150 \mu \mathrm{g} / \mathrm{mL})(\mathbf{A}, \mathbf{C})$ concentrations. Data are displayed relative to untreated control pellets. (A) Pooled data (mean \pm SEM) were derived from experiments with three different $\mathrm{hMSC}$ donors with each donor being analyzed in triplicate in one or two independent experiments $(n=9-18)$. (B, C) All replicates for each donor tested are shown (horizontal lines show mean). $* p<0.05$, ** $p<0.01$, *** $p<0.001$, versus GDF5-only treatment. "\# $p<0.01$, \#\# $p<0.001$, comparing GAGs of same dose.

\section{Pericellular heparan sulfate proteoglycans play an important role in localizing GDF5 to the surface of ATDC5 cells}

Heparan sulfate proteoglycans (HSPGs) are important in regulating the interaction of many soluble factors within the pericellular zone. To investigate the role of HSPGs in localizing GDF5 to the cell surface, we studied GDF5 binding to ATDC5 cells with and without specific degradation of HSPGs with heparinase enzymes; flow cytometry was used to quantitate the amount of cell surface GDF5 and HS, where the latter was determined using an antibody able to recognize a common epitope in HS $(10 \mathrm{E} 4)^{75}$ (Fig. 7A-C). As can be seen from Figure $7 \mathrm{~A}$ and $\mathrm{B}$, heparinase treatment reduced the amount of HS and the amount of GDF5 binding on ATDC5 cells in a dose-dependent manner. Goodness of fit linear regression analysis comparing the relationship between percentage cell surface GDF5 and HS showed a significant positive correlation $\left(\mathrm{R}^{2}=0.97, p<0.0001\right)$ (Fig. 7C).

\section{Exogenous heparin, but not equivalent doses of HS, dose dependently inhibits GDF5 binding to the surface of ATDC5 cells}

Having established that GDF5 binds to the cell surface by an interaction with HSPGs, we next investigated the ability of exogenously added GAG to perturb this interaction 

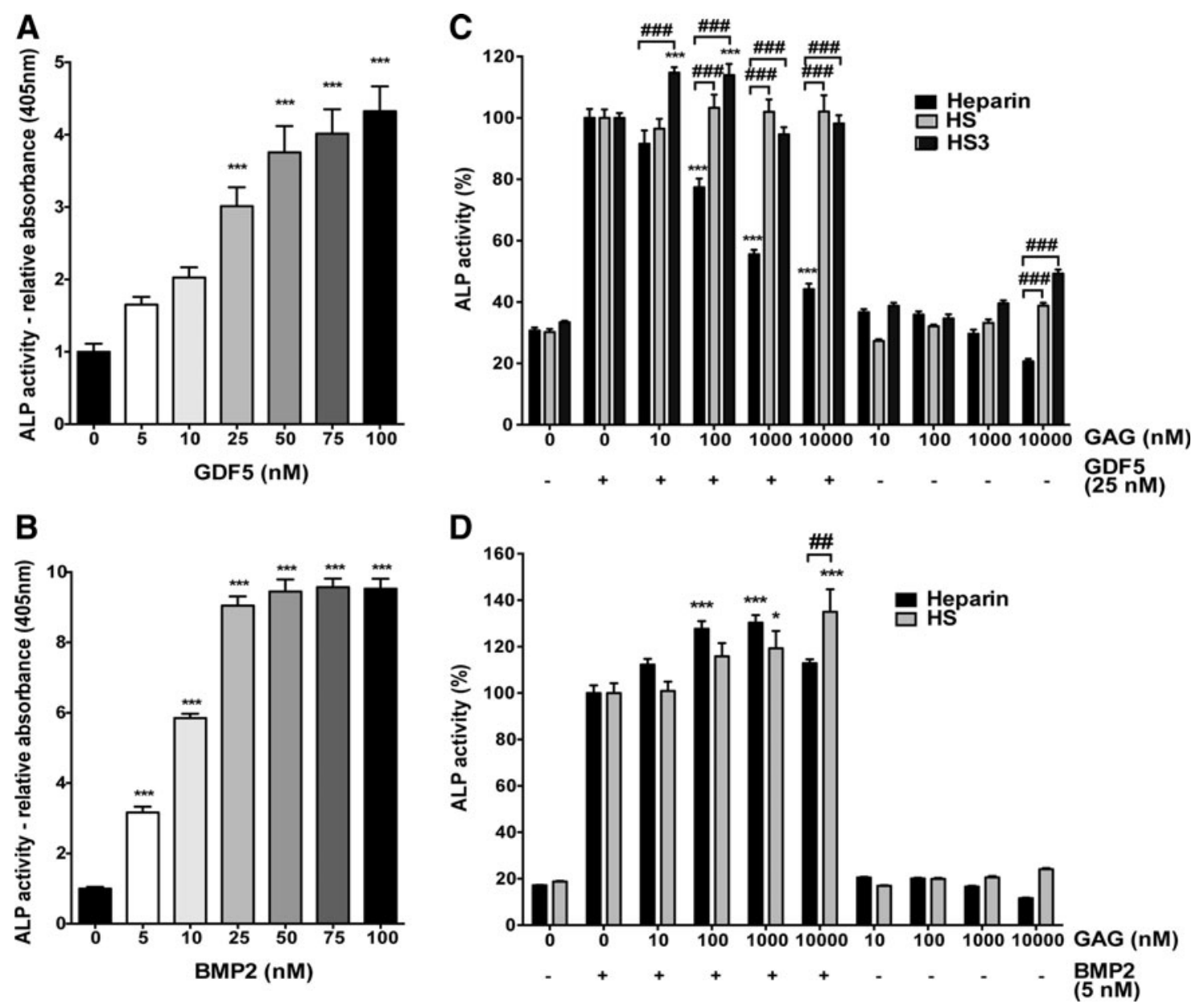

FIG. 6. Heparin, but not HS, inhibits GDF5-induced osteogenic differentiation of chondrogenic ATDC5 cells. GDF5 (A) and BMP2 (B) were used to stimulate ALP activity in ATDC5 cells for 3 days. The effect of GAGs in modulating GDF5(C) and BMP2- (D) induced ALP activity was investigated using the same method as in (A, B). Results are shown as mean \pm SEM, where experiments with GDF5 (A) and GAGs (C, D) were repeated three times, with each independent experiment being done in triplicate; BMP2 dosing (B) was analyzed in one experiment, performed in triplicate. ${ }^{*} p<0.05$, $* * * p<0.001$, versus untreated control $(\mathbf{A}, \mathbf{B})$, or versus GDF5-only control $(\mathbf{C}, \mathbf{D}) .{ }^{\# \#} p<0.01$, ${ }^{\# \# \#} p<0.001$, versus GAGs of same dose $(\mathbf{C}, \mathbf{D})$. ALP, alkaline phosphatase; BMP2, bone morphogenetic protein 2.

(competitive inhibition). Flow cytometric analysis demonstrated that exogenous heparin was indeed able to inhibit GDF5 binding to the cell surface $(p<0.0001)$ (Fig. 8A). Post hoc analysis demonstrated that a significant inhibition in binding was seen with doses $\geq 10 \mathrm{nM}$ heparin, with a $45.5 \%$ reduction in binding $(p<0.0001)$ at the $10 \mathrm{nM}$ dose. In contrast, exogenous HS was only able to outcompete endogenous HSPGs for GDF5 binding at the highest dose tested $(10,000 \mathrm{nM})$, where a $77.3 \%$ reduction in binding was observed $(p<0.05)$ (Fig. 8A). Notably, exogenous heparin at the same high dose $(10,000 \mathrm{nM})$ reduced GDF5-binding by $94 \%$. Semilog nonlinear regression analysis revealed that the relationship between the dose of GAG and amount of GDF5 bound to the cell surface was stronger for heparin $\left(\mathrm{R}^{2}=0.67\right)$ than $\mathrm{HS}\left(\mathrm{R}^{2}=0.32\right)(\mathrm{Fig} .8 \mathrm{~B})$.

Given the observed differences in the ability of heparin and HS to outcompete cell surface HSPGs for GDF5 binding, we next investigated the structural requirements of heparin for GDF5 binding, namely sugar chain size and types of sulfation. Only heparin fragments of dp18 $(p<0.05)$ and $\operatorname{dp} 26(p<0.001)$ were able to outcompete the binding of GDF5 to cell surface HSPG (Fig. 8C). Post hoc testing showed that this inhibitory effect was only significant at the highest dose of $10,000 \mathrm{nM}$ for dp18 $(p<0.05)$ and at doses $\geq 1000 \mathrm{nM}$ for dp26 ( $p<0.01)$. Importantly, this strong inhibitory effect was equal to that from similar doses of unfractionated heparin. None of the smaller sized heparin fragments (dp4-dp10) were able to inhibit GDF5 binding. Semilog nonlinear regression analysis revealed that a relationship between the dose of GAG and the amount of GDF5 bound to the cell surface was only apparent for dp26 $\left(\mathrm{R}^{2}=0.60\right.$ compared to 0.30 for dp18) (Fig. 8D). In addition, we found that while loss of $\mathrm{N}$-sulfation greatly reduced the ability of heparin to inhibit GDF5 binding, re-N-acetylation (following $\mathrm{N}$-desulfation) or removal of 6-O-sulfation only partially reduced the competitive effect of heparin (Fig. 8E). In addition, loss of 2-O-sulfation had little effect on the ability of heparin to compete. Only a weak relationship between the dose of GAG and amount of GDF5 bound to the cell surface was seen, and only for the N-desulfated/re-Nacetylated fraction $\left(\mathrm{R}^{2}=0.43\right)$ (Fig. $\left.8 \mathrm{~F}\right)$. 

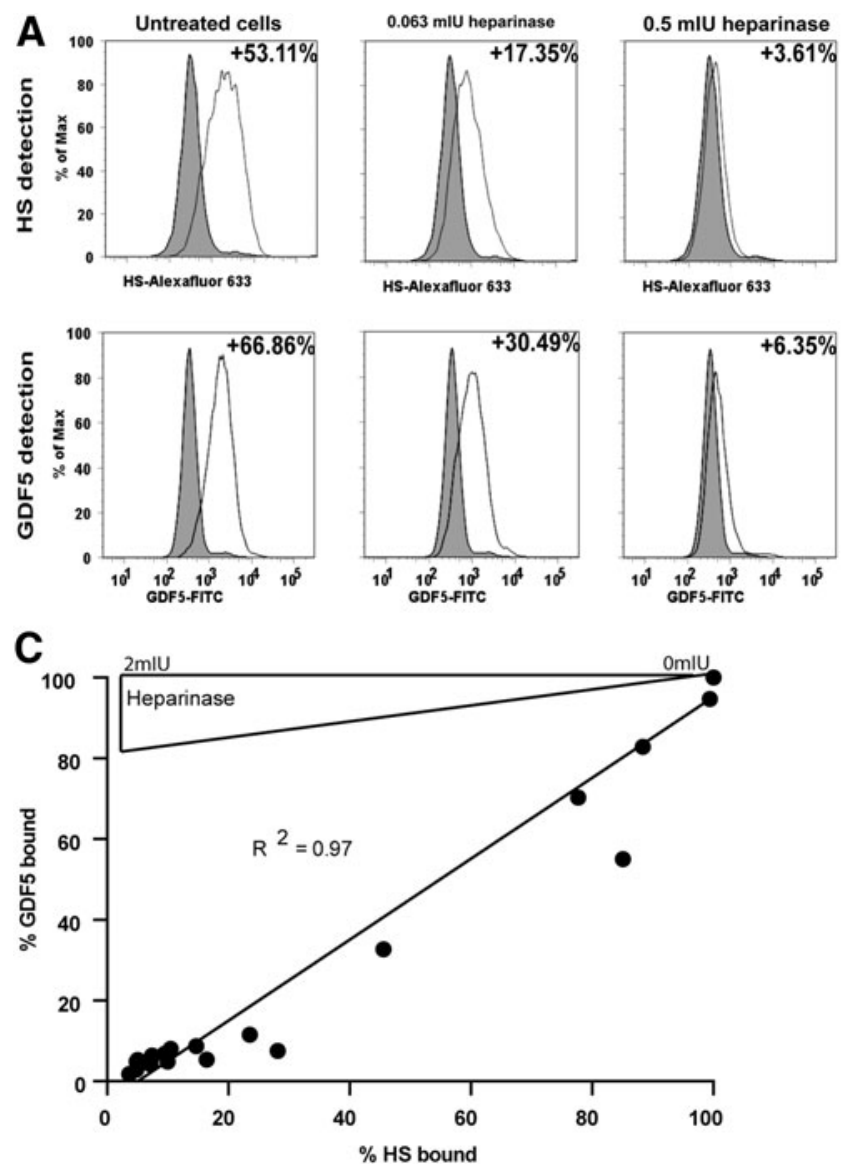

Heparin inhibits GDF5-mediated Smad 1/5/8 signaling in ATDC5 cells

GDF5 is known to signal through the Smad 1/5/8 pathway. To better understand the inhibitory effect of heparin on the GDF5-induced biological activity, we chose to maximally stimulate the Smad 1/5/8 phosphorylation with GDF5 and then investigate the impact of GAG on this pathway. We observed that GDF5-induced Smad 1/5/8 phosphorylation was inhibited by exogenous heparin $(p<0.05)$ (Fig. 9A, B), a finding that parallels heparin's inhibitory effect on aggrecan expression and ALP activity. Significant Smad 1/ $5 / 8$ inhibition was seen at heparin doses $\geq 100 \mathrm{nM}$ (3.2-fold decrease, $p<0.05)$. In addition, the detected amount of GDF5 (cell associated) was reduced following heparin treatment, in strong agreement with the flow cytometry data shown in Figure 8A. In comparison, HS had no inhibitory effect on GDF5-induced Smad 1/5/8 activation and no differences were observed in the amount of GDF5 able to bind to the cells in the presence of HS (Fig. 9C, D).

\section{Discussion}

hMSCs are a promising avenue for the regeneration of both osteochondral and chondral defects (see reviews Ayerst et al. ${ }^{6}$ and Makris et al. ${ }^{76}$ ). However, the relative benefits of growth factors, GAGs, and other bioactive or mechanical stimuli for the promotion of their differentiation are still far from clear, and issues remain with regard to the quality of tissue that can be generated. In this study, we provide evidence that the inclusion of GDF5 may help to overcome a major hurdle in cartilage TE

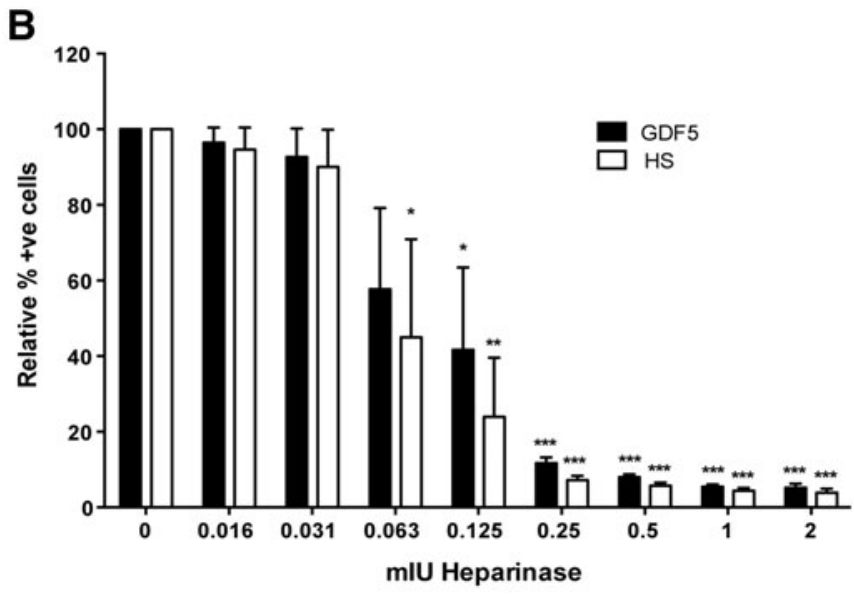

FIG. 7. Endogenous HSPGs play an important role in localizing GDF5 to the surface of ATDC5 cells. HSPGs were enzymatically removed from the ATDC5 cells using increasing concentrations of heparinases I, II, and III, and cells were then incubated with GDF5. Cells positive for HSPG and bound GDF5 were detected by flow cytometry with HSPGand GDF5-specific antibodies; representative histograms are shown (A). Data (mean \pm SEM) were derived from three independent experiments and the numbers of HSPG-/GDF5positive cells were calculated relative to untreated cells incubated with GDF5 (B). Correlation between \% HS and \% GDF5 bound to the cell surface was then evaluated $(\mathbf{C})$. $* p<0.05, * * p<0.01, * * * p<0.001$, versus control (no heparinase). HSPGs, heparan sulfate proteoglycans.

strategies, by promoting the chondrogenic differentiation of hMSCs, without inducing hypertrophy, a common problem for methodologies that employ the use of TGF $\beta 1 / 3$ for inducing differentiation. ${ }^{45,70,77,78}$ In contrast to TGF $\beta 1$, we found that GDF5 induced the aggrecan and sox 9 expression without increasing the expression of collagen $\mathrm{X}$. This combination suggests that GDF5 could be used to generate a clinically useful cartilage matrix with a high proteoglycan content, while maintaining the chondrocytes in a mature articular phenotype.

Our results are generally in agreement with previous studies comparing the effects of TGF $\beta$ and GDF5 on chondrogenesis. ${ }^{47,79}$ However, our results contrast with those suggesting that GDF5 can promote the hypertrophy of hMSC-derived chondrocyte pellets. ${ }^{80}$ This previous study, however, looked at the effect of GDF5 in combination with TGF $\beta 3$, and not in isolation. While the combination of both TGF $\beta 3$ and GDF5 promoted hypertrophy, we have demonstrated that GDF5 alone does not increase collagen type X expression and the combination of GDF5 and TGF $\beta 1$ is no more potent at inducing collagen $X$ than TGF $\beta 1$ treatment alone. In addition, consistent with what we are seeing, work in an osteoarthritis rat model has also demonstrated that GDF5 is expressed in healthy prehypertrophic cartilage, but is not evident as osteoarthritis develops. ${ }^{81}$

A further study with human chondrocytes showed that GDF5 stimulation promoted the expression of aggrecan, while inhibiting collagen type $\mathrm{X}$ expression. ${ }^{40}$ Overall, there is increasing evidence supporting the potential use of GDF5 in cartilage TE strategies, especially when this growth factor is supplied to hMSCs in the absence of TGF $\beta$. Histological 

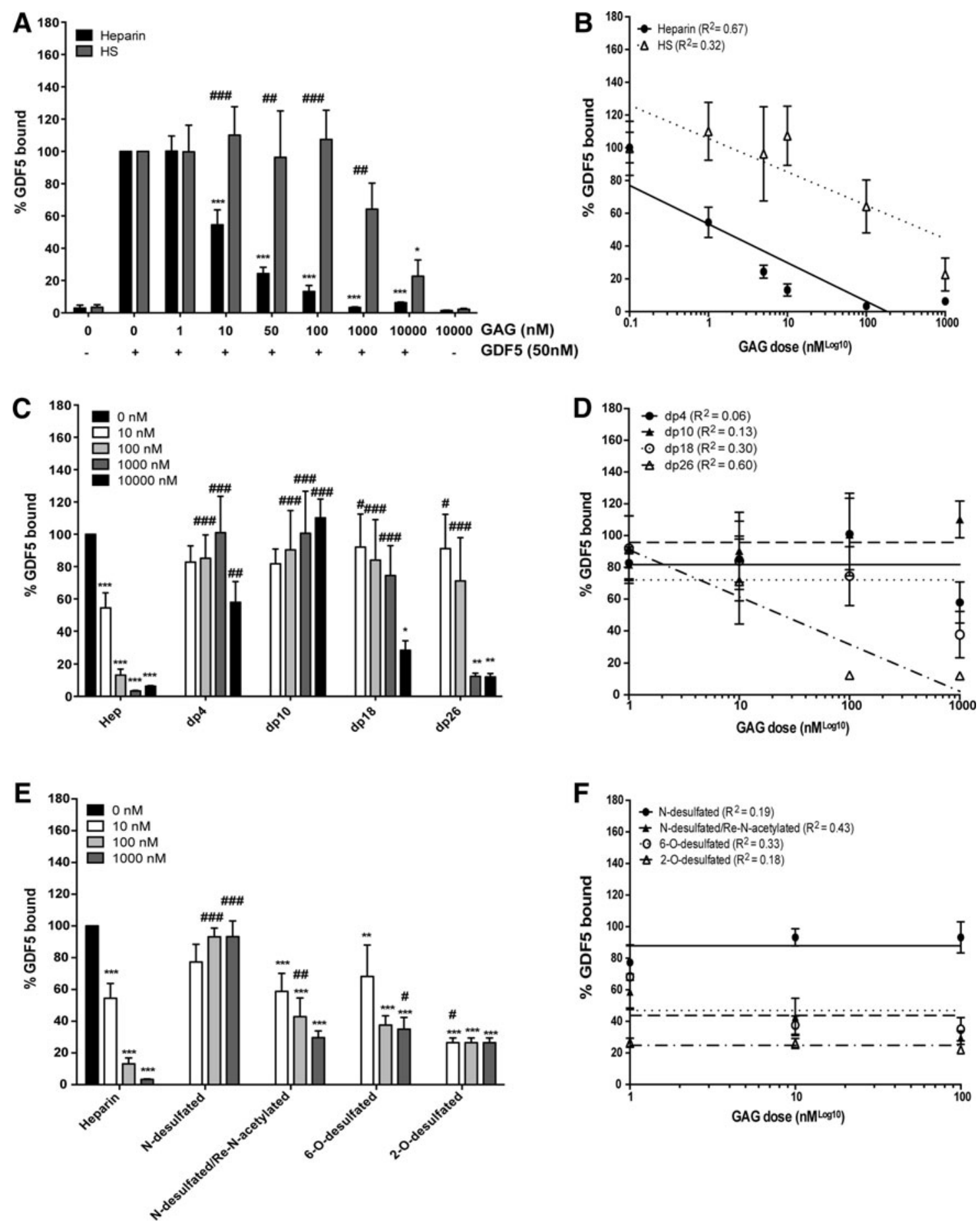

FIG. 8. Exogenous heparin, but not equivalent doses of HS, inhibits GDF5 binding to the surface of ATDC5 cells. The effect of unfractionated heparin/HS (A, B), heparin oligosaccharides (dp; number of monosaccharides) (C, D), and selectively desulfated heparin (E, F) on GDF5 binding to ATDC5 cells was analyzed using flow cytometry (A, C, E). Data (mean \pm SEM) were derived from three independent experiments with median fluorescence intensities being used to calculate the percentage of GDF5 bound to the cell surface relative to GDF5 treatment alone. Nonlinear regression analysis was carried out to look at the relationship between dose of GAG and amount of GDF5 able to bind to the cell surface (B, D, F). $* * p<0.01$, *** $p<0.001$, versus GDF5-only control (black bar; no heparin/HS treatment). ${ }^{*} p<0.05$, ${ }^{\# \#} p<0.01$, \# $p<0.001$, versus GAGs of same dose (A), or versus unfractionated heparin of same dose (B, C). dp, degree of polymerization. 

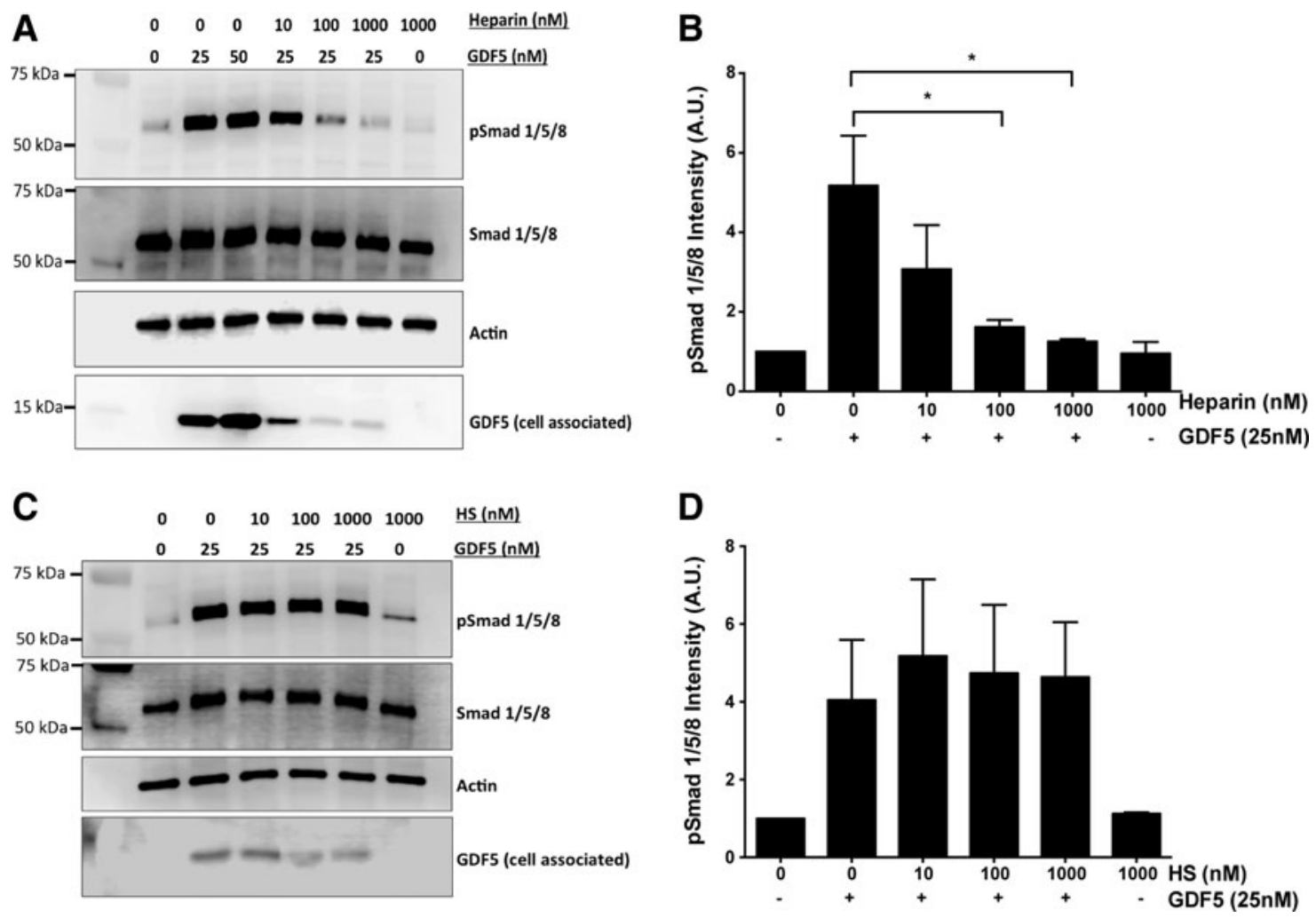

FIG. 9. Heparin inhibits GDF5-mediated Smad 1/5/8 signaling in ATDC5 cells. Serum-starved ATDC5 cells were treated with GDF5 alone, or with GDF5 plus heparin $(\mathbf{A}, \mathbf{B})$ or HS $(\mathbf{C}, \mathbf{D})$. Cells were stimulated for $1 \mathrm{~h}$ before being harvested for Western blot analysis. Three independent experiments were carried out, with $(\mathbf{A}, \mathbf{C})$ showing representative blots. p-Smad 1/5/8 levels were determined relative to total Smad 1/5/8 and actin levels using densitometry (B, D), and results are displayed as mean \pm SEM. $* p<0.05$.

analysis and protein expression studies would be a valuable next step to complement and extend the gene expression work we have carried out in this study, as has been done previously with TGF $\beta 1 / 3 .^{45,70}$ In addition, it would also be interesting to see whether continued treatment of pellet cultures with GDF5 (i.e., for longer than 21 days) would eventually induce hypertrophy or whether the chondrocytes would maintain an articular phenotype. It is also worth noting that, although commercially available hMSCs are widely used in studies, ${ }^{31,82,83}$ continued development using freshly isolated cells to look at the effects of aging populations and changes in the bone-marrow microenvironments will also indeed be important. ${ }^{84}$ Intriguingly, recent work in human umbilical cord perivascular stem cell-derived chondrocyte pellets demonstrated that GDF5 enhanced proliferation, but had no effect on the expression of chondrogenic-related genes, ${ }^{85}$ therefore suggesting that the effect of GDF5 may also be stem/stromal cell source specific.

The potential of GDF5 for cartilage TE, along with the increasing inclusion of heparin in biomaterials for bone and cartilage regeneration, ${ }^{7,23,24,86-89}$ meant that investigating the interaction between GDF5 and heparin was a natural next step for our study. While a number of the TGF $\beta$ superfamily members have already been shown to bind heparin, $50,51,68,90$ this interaction does not appear to be a universal property of all proteins with this fold. ${ }^{51}$ The GDF subfamily comprises approximately one third of the TGF $\beta$ superfamily, although as yet, an interaction with heparin has only been determined for GDF9. ${ }^{90}$ In this study, we identified GDF5 as a novel heparin/
HS binding protein, using SPR and DSF. ${ }^{50,65,91}$ For example, GDF5 was found to bind heparin with high affinity $\left(K_{\mathrm{D}}<\right.$ $100 \mathrm{nM})$, in agreement with a study reporting that proteins involved in skeletal system development display high or very high affinity for heparin. ${ }^{92}$ We also demonstrated that pericellular HSPGs play a key role in localizing GDF5 to the cell surface, which is in good agreement with results reported for BMP2. ${ }^{26,93}$ It further emphasizes the importance of HSPGs in regulating the activity of many TGF $\beta$ superfamily members.

Treatment with exogenous heparin is also generally thought to potentiate the bioactivity of TGF $\beta$ superfamily members, ${ }^{26,50,94}$ leading to its incorporation into a number of biomaterials to improve skeletal TE strategies. It should be noted, however, that some inhibitory effects of heparin on TGF $\beta$ superfamily members (and other proteins) have been reported when high doses of the GAG are used. ${ }^{95,96}$ Despite this, heparin is still being widely incorporated into biomaterials for TE strategies. ${ }^{86,88,97-99}$ Importantly, our data demonstrate that heparin has a strong and clear inhibitory effect on the biological activity of GDF5, even at doses 10-fold lower than those that would be clinically administered. For example, for patients with venous thromboembolism, the dose of heparin is usually maintained at $0.3-$ $0.7 \mathrm{U} / \mathrm{mL},{ }^{100}$ while $10 \mathrm{nM}$ of heparin used in this study equates to around $0.03-0.04 \mathrm{U} / \mathrm{mL}$. In addition, this inhibitory effect was seen across multiple hMSC donors and in the skeletal cell line ATDC5. Given the importance of GDF5 for skeletal development, our results might help explain the reported increased risk of developing osteoporosis following 
long-term heparin treatment, ${ }^{29,30}$ and the variable (and disappointing) results seen with heparin-loaded biomaterials for skeletal repair. ${ }^{25,26}$ In addition these data support our previous findings demonstrating that heparin can impair the biological properties and molecular signature of hMSCs, ${ }^{31}$ and as a whole, adds further caution to the widespread use of unfractionated heparin, both in the clinic and research settings.

Importantly, the HS used in this study did not show the same inhibitory effect as heparin on GDF5 activity, indicating that in general, HS may be a more suitable, safe, and effective alternative for incorporation into TE strategies and stem cell expansion/differentiation protocols. Although heparin and $\mathrm{HS}$ are both polydisperse and heterogeneous in nature, heparin is intrinsically more heavily sulfated than $\mathrm{HS},{ }^{101,102}$ which is likely responsible for its strong inhibitory effect on GDF5 activity. While the unfractionated HS preparation did not inhibit GDF5 activity, it did not significantly promote the activity of the growth factor either. However, given the sequence diversity of $\mathrm{HS}$, we anticipate that it will be possible to identify HS variants that promote GDF5 activity, while retaining other beneficial effects on chondrocyte function/phenotype. Our previous work and ongoing investigations indicate that the isolation or synthesis of HS variants, for example those based on their affinity for particular growth factors, enables the selection of saccharides markedly more potent at promoting the bioactivity of growth factors compared to using unfractionated HS starting material, with its intrinsically high level of compositional heterogeneity. ${ }^{26,59,68,69}$ Thus, there is the possibility to potentiate the activity of specific growth factors, to the same or greater extent than heparin, while avoiding the adverse and off-target effects of heparin caused by its pleiotropic nature. Indeed, in this study, we have shown that the HS3 variant (selected through its affinity for BMP2 and shown to be effective in promoting BMP2 bioactivity ${ }^{68,69}$ ) could not inhibit the GDF5-induced ALP activity in the same manner as heparin. Therefore, by using this particular HS3 variant, there is the possibility of promoting BMP2 activity (as with heparin) without affecting the activity of GDF5, which would also be at the injury site and important for the repair process. This further highlights the therapeutic utility of developing selective HS variants, rather than using heparin. Interestingly, given that HS3 is more highly sulfated than unfractionated $\mathrm{HS}^{68}$ and carries an overall charge more similar to heparin, we would have expected HS3 to act in a similar inhibitory manner to heparin with regard to its effects on the GDF5induced ALP activity. However, this was not the case and suggests that charge density is not the dominant feature in the interaction between GDF5 and heparin/HS, and GAG structure and sequence may also play a role. It is also worth noting that HS has a significantly lower anticoagulant activity compared to heparin ${ }^{103,104}$ and so its use over heparin may also help negate undesirable side effects such as heparininduced thrombocytopenia.

This then prompted us to investigate the role of sugar chain size and specific sulfation pattern on GDF5 binding. We demonstrated that only the longest heparin-derived oligosaccharides tested (dp18 and dp26) at the higher doses tested were able to competitively inhibit GDF5 binding to the cell surface; implying that the heparin must contact a large extended binding site on the protein or span between two subsites. It is also possible that, in a similar manner to the proposed model for heparin-TGF $\beta 1$ binding, ${ }^{50}$ long heparin/HS chains may bridge the gap between the heparin binding sites on each of the GDF5 monomers, although further studies would be needed to identify whether this is indeed the case. However, given that HS chains typically range from 10 to $70 \mathrm{kDa}^{2}$ and a dp26 oligosaccharide has an average MW of only $7.4 \mathrm{kDa}$, it is entirely plausible that longer heparin/HS chains are usually required for GDF5 binding. In addition, the fact that HSPGs on the cell surface of ATDC5 cells were found to bind very effectively to GDF5, but that the exogenous HS used in this study was a poor competitor of this binding, suggests that the HS used in this study has a low content of these longer sequences that are required for GDF5 binding.

In contrast to the relatively discrete requirement for longer heparin-derived sequences to inhibit the bioactivity of GDF5, the use of desulfated heparin preparations demonstrated no clear requirement for a specific modification. While $\mathrm{N}$ desulfation prevented heparin from being able to competitively inhibit GDF5 binding to pericellular HSPGs, re-N-acetylation largely recovered this ability. This suggests that $\mathrm{N}$-desulfation is not essential for the ability of heparin chains to bind GDF5 and instead, the free positively charged amino groups $\left(\mathrm{NH}_{3}^{+}\right)$ remaining following $\mathrm{N}$-desulfation inhibit the ability of heparin to bind GDF5. The functional significance of this is unclear, given that free amines within heparin/HS chains are thought to be relatively rare, usually ranging from $0.2 \%$ to $4 \%$ of disaccharide units. ${ }^{63,105,106} 2$-O-sulfation was not found to be crucial for the interaction with GDF5. The importance of 6-O-sulfation was not clear, particularly given that around $25 \%$ of $2-\mathrm{O}-$ sulfates are also lost during 6-O-desulfation. Pulling the data together, it may be that there is a requirement for a highly sulfated sequence, rather than a particular dependence on a specific type of sulfation. In addition, it is important to consider that the more rare 3-O-sulfation, which would be included in longer heparin fragments and would also occasionally appear in HS, may play an important role.

\section{Conclusion}

The formation of hypertrophic rather than hyaline (articular) chondrocytes from hMSCs is a major limitation in current cartilage TE strategies. Supplementation of hMSCs with GDF5 rather than TGF $\beta 1 / 3$ may provide a more effective way to overcome this hurdle, and warrants further investigation. In addition, the inhibitory effect of heparin on the GDF5 activity (along with the adverse effects of heparin already reported) adds further precaution to its widespread use in the clinic and in TE applications, and urges the transition to using more specific sugars with less off-target effects (e.g., HS derivatives or synthetics), if optimal therapy is to be achieved.

\section{Acknowledgments}

The authors are grateful for the financial support from the Biomedical Research Council, Agency for Science, Technology and Research (A*STAR) Singapore, Singapore), and the Institute of Medical Biology, A*STAR (Singapore, Singapore). B.I.A. acknowledges the receipt of a University of Manchester and A*STAR (Singapore, Singapore) PhD Studentship and A*STAR Research Attachment Programme (ARAP) scholarship. We would also like to thank Elaine Gray from the National Institute for Biological Standards and Control (NIBSC), United Kingdom, and Tom Jowitt 
from the Biomolecular Analysis Facility at the University of Manchester (Manchester, United Kingdom), for their helpful advice.

\section{Authors' Contributions}

B.I.A. designed and performed the experiments, analyzed the data, and wrote the article R.A.A.S. helped with the HS fractionation. S.M.C., A.J.D., C.L.R.M., and V.N. also contributed in designing and analyzing the data, oversaw the research, and contributed to writing the article. All authors analyzed the results and approved the final version of the article.

\section{Disclosure Statement}

No competing financial interests exist.

\section{References}

1. Xu, D., and Esko, J.D. Demystifying heparan sulfateprotein interactions. Annu Rev Biochem 83, 129, 2014.

2. Esko, J.D., Kimata, K., and Lindahl, U. Proteoglycans and sulfated glycosaminoglycans. In: Varki, A., Cummings, R.D., Esko, J.D., Freeze, H.H., Stanley, P., Bertozzi, C.R., et al., eds. Essentials of Glycobiology, 2nd ed. New York: Cold Spring Harbor, 2009, pp. 229-248.

3. Weitz, J.I. Heparan sulfate: antithrombotic or not? J Clin Invest 111, 952, 2003.

4. Lever, R., and Page, C.P. Novel drug development opportunities for heparin. Nat Rev Drug Discov 1, 140, 2002.

5. Page, C. Heparin and related drugs: beyond anticoagulant activity. ISRN Pharmacol 2013, 910743, 2013.

6. Ayerst, B.I., Day, A.J., Nurcombe, V., Cool, S.M., and Merry, C.L. New strategies for cartilage regeneration exploiting selected glycosaminoglycans to enhance cell fate determination. Biochem Soc Trans 42, 703, 2014.

7. Bhakta, G., Rai, B., Lim, Z.X., Hui, J.H., Stein, G.S., van Wijnen, A.J., Nurcombe, V., Prestwich, G.D., and Cool, S.M. Hyaluronic acid-based hydrogels functionalized with heparin that support controlled release of bioactive BMP2. Biomaterials 33, 6113, 2012.

8. Goonasekera, C.S., Jack, K.S., Bhakta, G., Rai, B., LuongVan, E., Nurcombe, V., Cool, S.M., Cooper-White, J.J., and Grondahl, L. Mode of heparin attachment to nanocrystalline hydroxyapatite affects its interaction with bone morphogenetic protein-2. Biointerphases 10, 04A308, 2015.

9. Roelofs, L.A., Oosterwijk, E., Kortmann, B.B., Daamen, W.F., Tiemessen, D.M., Brouwer, K.M., Eggink, A.J., Crevels, A.J., Wijnen, R.M., van Kuppevelt, T.H., Geutjes, P.J., and Feitz, W.F. Bladder regeneration using a smart acellular collagen scaffold with growth factors VEGF, FGF2 and HB-EGF. Tissue Eng Part A 22, 83, 2016.

10. Wang, J., An, Q., Li, D., Wu, T., Chen, W., Sun, B., ElHamshary, H., Al-Deyab, S.S., Zhu, W., and Mo, X. Heparin and vascular endothelial growth factor loaded poly(Llactide-co-caprolactone) nanofiber covered stent-graft for aneurysm treatment. J Biomed Nanotechnol 11, 1947, 2015.

11. Furue, M.K., Na, J., Jackson, J.P., Okamoto, T., Jones, M., Baker, D., Hata, R., Moore, H.D., Sato, J.D., and Andrews, P.W. Heparin promotes the growth of human embryonic stem cells in a defined serum-free medium. Proc Natl Acad Sci U S A 105, 13409, 2008.

12. Ling, L., Dombrowski, C., Foong, K.M., Haupt, L.M., Stein, G.S., Nurcombe, V., van Wijnen, A.J., and Cool,
S.M. Synergism between Wnt3a and heparin enhances osteogenesis via a phosphoinositide 3-kinase/Akt/RUNX2 pathway. J Biol Chem 285, 26233, 2010.

13. Meade, K.A., White, K.J., Pickford, C.E., Holley, R.J., Marson, A., Tillotson, D., van Kuppevelt, T.H., Whittle, J.D., Day, A.J., and Merry, C.L. Immobilization of heparan sulfate on electrospun meshes to support embryonic stem cell culture and differentiation. J Biol Chem 288, 5530, 2013.

14. Uygun, B.E., Stojsih, S.E., and Matthew, H.W. Effects of immobilized glycosaminoglycans on the proliferation and differentiation of mesenchymal stem cells. Tissue Eng Part A 15, 3499, 2009.

15. Prince, M.J., Wu, F., Guo, Y., Gutierrez Robledo, L.M., O'Donnell, M., Sullivan, R., and Yusuf, S. The burden of disease in older people and implications for health policy and practice. Lancet 385, 549, 2015.

16. Woolf, A.D., and Pfleger, B. Burden of major musculoskeletal conditions. Bull World Health Organ 81, 646, 2003.

17. Amini, A.R., Laurencin, C.T., and Nukavarapu, S.P. Bone tissue engineering: recent advances and challenges. Crit Rev Biomed Eng 40, 363, 2012.

18. Dhinsa, B.S., and Adesida, A.B. Current clinical therapies for cartilage repair, their limitation and the role of stem cells. Curr Stem Cell Res Ther 7, 143, 2012.

19. Carreira, A.C., Alves, G.G., Zambuzzi, W.F., Sogayar, M.C., and Granjeiro, J.M. Bone morphogenetic proteins: structure, biological function and therapeutic applications. Arch Biochem Biophys 561, 64, 2014.

20. Martino, M.M., Briquez, P.S., Maruyama, K., and Hubbell, J.A. Extracellular matrix-inspired growth factor delivery systems for bone regeneration. Adv Drug Deliv Rev 94, 41, 2015.

21. Carragee, E.J., Chu, G., Rohatgi, R., Hurwitz, E.L., Weiner, B.K., Yoon, S.T., Comer, G., and Kopjar, B. Cancer risk after use of recombinant bone morphogenetic protein-2 for spinal arthrodesis. J Bone Joint Surg Am 95, 1537, 2013.

22. Devine, J.G., Dettori, J.R., France, J.C., Brodt, E., and McGuire, R.A. The use of rhBMP in spine surgery: is there a cancer risk? Evid Based Spine Care J 3, 35, 2012.

23. Hettiaratchi, M.H., Miller, T., Temenoff, J.S., Guldberg, R.E., and McDevitt, T.C. Heparin microparticle effects on presentation and bioactivity of bone morphogenetic protein-2. Biomaterials 35, 7228, 2014.

24. Yang, H.S., La, W.G., Bhang, S.H., Jeon, J.Y., Lee, J.H., and Kim, B.S. Heparin-conjugated fibrin as an injectable system for sustained delivery of bone morphogenetic protein-2. Tissue Eng Part A 16, 1225, 2010.

25. Koo, K.H., Lee, J.M., Ahn, J.M., Kim, B.S., La, W.G., Kim, C.S., and Im, G.I. Controlled delivery of low-dose bone morphogenetic protein-2 using heparin-conjugated fibrin in the posterolateral lumbar fusion of rabbits. Artif Organs 37, 487, 2013.

26. Bramono, D.S., Murali, S., Rai, B., Ling, L., Poh, W.T., Lim, Z.X., Stein, G.S., Nurcombe, V., van Wijnen, A.J., and Cool, S.M. Bone marrow-derived heparan sulfate potentiates the osteogenic activity of bone morphogenetic protein-2 (BMP-2). Bone 50, 954, 2012.

27. Bambrah, R.K., Pham, D.C., Zaiden, R., Vu, H., and Tai, S. Heparin-induced thrombocytopenia. Clin Adv Hematol Oncol 9, 594, 2011.

28. Bounameaux, H., Schneider, P.A., Mossaz, A., Suter, P., and Vasey, H. Severe vasospastic reactions (ergotism) during 
prophylactic administration of heparin-dihydroergotamine. Vasa 16, 370, 1987.

29. Mazziotti, G., Canalis, E., and Giustina, A. Drug-induced osteoporosis: mechanisms and clinical implications. Am J Med 123, 877, 2010.

30. Sackler, J.P., and Liu, L. Heparin-induced osteoporosis. Br J Radiol 46, 548, 1973.

31. Ling, L., Camilleri, E.T., Helledie, T., Samsonraj, R.M., Titmarsh, D.M., Chua, R.J., Dreesen, O., Dombrowski, C., Rider, D.A., Galindo, M., Lee, I., Hong, W., Hui, J.H., Nurcombe, V., van Wijnen, A.J., and Cool, S.M. Effect of heparin on the biological properties and molecular signature of human mesenchymal stem cells. Gene 576, 292, 2016.

32. Chang, S.C., Hoang, B., Thomas, J.T., Vukicevic, S., Luyten, F.P., Ryba, N.J., Kozak, C.A., Reddi, A.H., and Moos, M., Jr. Cartilage-derived morphogenetic proteins. New members of the transforming growth factor-beta superfamily predominantly expressed in long bones during human embryonic development. J Biol Chem 269, $28227,1994$.

33. Kwong, F.N., Hoyland, J.A., Evans, C.H., and Freemont, A.J. Regional and cellular localisation of BMPs and their inhibitors' expression in human fractures. Int Orthop 33, 281, 2009.

34. Storm, E.E., and Kingsley, D.M. GDF5 coordinates bone and joint formation during digit development. Dev Biol 209, 11, 1999.

35. Storm, E.E., Huynh, T.V., Copeland, N.G., Jenkins, N.A., Kingsley, D.M., and Lee, S.J. Limb alterations in brachypodism mice due to mutations in a new member of the TGF beta-superfamily. Nature 368, 639, 1994.

36. Thomas, J.T., Kilpatrick, M.W., Lin, K., Erlacher, L., Lembessis, P., Costa, T., Tsipouras, P., and Luyten, F.P. Disruption of human limb morphogenesis by a dominant negative mutation in CDMP1. Nat Genet 17, 58, 1997.

37. Miyamoto, Y., Mabuchi, A., Shi, D., Kubo, T., Takatori, Y., Saito, S., Fujioka, M., Sudo, A., Uchida, A., Yamamoto, S., Ozaki, K., Takigawa, M., Tanaka, T., Nakamura, Y., Jiang, Q., and Ikegawa, S. A functional polymorphism in the 5' UTR of GDF5 is associated with susceptibility to osteoarthritis. Nat Genet 39, 529, 2007.

38. Dawson, K., Seeman, P., Sebald, E., King, L., Edwards, M., Williams, J., 3rd, Mundlos, S., and Krakow, D. GDF5 is a second locus for multiple-synostosis syndrome. Am J Hum Genet 78, 708, 2006.

39. Degenkolbe, E., Konig, J., Zimmer, J., Walther, M., Reissner, C., Nickel, J., Ploger, F., Raspopovic, J., Sharpe, J., Dathe, K., Hecht, J.T., Mundlos, S., Doelken, S.C., and Seemann, P. A GDF5 point mutation strikes twice-causing BDA1 and SYNS2. PLoS Genet 9, e1003846, 2013.

40. Enochson, L., Stenberg, J., Brittberg, M., and Lindahl, A. GDF5 reduces MMP13 expression in human chondrocytes via DKK1 mediated canonical Wnt signaling inhibition. Osteoarthritis Cartilage 22, 566, 2014.

41. Le Blanc, K., Tammik, C., Rosendahl, K., Zetterberg, E., and Ringden, O. HLA expression and immunologic properties of differentiated and undifferentiated mesenchymal stem cells. Exp Hematol 31, 890, 2003.

42. Chamberlain, G., Fox, J., Ashton, B., and Middleton, J. Concise review: mesenchymal stem cells: their phenotype, differentiation capacity, immunological features, and potential for homing. Stem Cells 25, 2739, 2007.

43. Uccelli, A., Pistoia, V., and Moretta, L. Mesenchymal stem cells: a new strategy for immunosuppression? Trends Immunol 28, 219, 2007.
44. Atoui, R., and Chiu, R.C. Immune responses after mesenchymal stem cell implantation. Methods Mol Biol 1036, 107, 2013.

45. Johnstone, B., Hering, T.M., Caplan, A.I., Goldberg, V.M., and Yoo, J.U. In vitro chondrogenesis of bone marrow-derived mesenchymal progenitor cells. Exp Cell Res 238, 265, 1998.

46. Mueller, M.B., Fischer, M., Zellner, J., Berner, A., Dienstknecht, T., Prantl, L., Kujat, R., Nerlich, M., Tuan, R.S., and Angele, P. Hypertrophy in mesenchymal stem cell chondrogenesis: effect of TGF-beta isoforms and chondrogenic conditioning. Cells Tissues Organs 192, 158, 2010.

47. Murphy, M.K., Huey, D.J., Hu, J.C., and Athanasiou, K.A. TGF-beta1, GDF-5, and BMP-2 stimulation induces chondrogenesis in expanded human articular chondrocytes and marrow-derived stromal cells. Stem Cells 33, 762, 2015.

48. Zhang, B., Yang, S., Sun, Z., Zhang, Y., Xia, T., Xu, W., and Ye, S. Human mesenchymal stem cells induced by growth differentiation factor 5: an improved self-assembly tissue engineering method for cartilage repair. Tissue Eng Part C Methods 17, 1189, 2011.

49. Khan, S.A., Nelson, M.S., Pan, C., Gaffney, P.M., and Gupta, P. Endogenous heparan sulfate and heparin modulate bone morphogenetic protein-4 signaling and activity. Am J Physiol Cell Physiol 294, C1387, 2008.

50. Lee, J., Wee, S., Gunaratne, J., Chua, R.J., Smith, R.A., Ling, L., Fernig, D.G., Swaminathan, K., Nurcombe, V., and Cool, S.M. Structural determinants of heparintransforming growth factor-betal interactions and their effects on signaling. Glycobiology 25, 1491, 2015.

51. Lyon, M., Rushton, G., and Gallagher, J.T. The interaction of the transforming growth factor-betas with heparin/heparan sulfate is isoform-specific. J Biol Chem 272, 18000, 1997.

52. Rider, C.C. Heparin/heparan sulphate binding in the TGFbeta cytokine superfamily. Biochem Soc Trans 34, 458, 2006.

53. Ruppert, R., Hoffmann, E., and Sebald, W. Human bone morphogenetic protein 2 contains a heparin-binding site which modifies its biological activity. Eur J Biochem 237, 295, 1996.

54. Gandhi, N.S., and Mancera, R.L. Prediction of heparin binding sites in bone morphogenetic proteins (BMPs). Biochim Biophys Acta 1824, 1374, 2012.

55. Ai, X., Do, A.T., Lozynska, O., Kusche-Gullberg, M., Lindahl, U., and Emerson, C.P., Jr. QSulf1 remodels the 6-O sulfation states of cell surface heparan sulfate proteoglycans to promote Wnt signaling. J Cell Biol 162, 341, 2003.

56. Harmer, N.J., Robinson, C.J., Adam, L.E., Ilag, L.L., Robinson, C.V., Gallagher, J.T., and Blundell, T.L. Multimers of the fibroblast growth factor (FGF)-FGF receptorsaccharide complex are formed on long oligomers of heparin. Biochem J 393, 741, 2006.

57. Rider, D.A., Dombrowski, C., Sawyer, A.A., Ng, G.H., Leong, D., Hutmacher, D.W., Nurcombe, V., and Cool, S.M. Autocrine fibroblast growth factor 2 increases the multipotentiality of human adipose-derived mesenchymal stem cells. Stem Cells 26, 1598, 2008.

58. Samsonraj, R.M., Rai, B., Sathiyanathan, P., Puan, K.J., Rotzschke, O., Hui, J.H., Raghunath, M., Stanton, L.W., Nurcombe, V., and Cool, S.M. Establishing criteria for human mesenchymal stem cell potency. Stem Cells 33, 1878, 2015.

59. Wang, C., Poon, S., Murali, S., Koo, C.Y., Bell, T.J., Hinkley, S.F., Yeong, H., Bhakoo, K., Nurcombe, V., and 
Cool, S.M. Engineering a vascular endothelial growth factor 165-binding heparan sulfate for vascular therapy. Biomaterials 35, 6776, 2014.

60. Amara, A., Lorthioir, O., Valenzuela, A., Magerus, A., Thelen, M., Montes, M., Virelizier, J.L., Delepierre, M., Baleux, F., Lortat-Jacob, H., and Arenzana-Seisdedos, F. Stromal cell-derived factor-1alpha associates with heparan sulfates through the first beta-strand of the chemokine. J Biol Chem 274, 23916, 1999.

61. Futamura, M., Dhanasekaran, P., Handa, T., Phillips, M.C., Lund-Katz, S., and Saito, H. Two-step mechanism of binding of apolipoprotein E to heparin: implications for the kinetics of apolipoprotein E-heparan sulfate proteoglycan complex formation on cell surfaces. J Biol Chem 280, 5414, 2005.

62. Moulard, M., Lortat-Jacob, H., Mondor, I., Roca, G., Wyatt, R., Sodroski, J., Zhao, L., Olson, W., Kwong, P.D., and Sattentau, Q.J. Selective interactions of polyanions with basic surfaces on human immunodeficiency virus type 1 gp120. J Virol 74, 1948, 2000.

63. Osmond, R.I., Kett, W.C., Skett, S.E., and Coombe, D.R. Protein-heparin interactions measured by BIAcore 2000 are affected by the method of heparin immobilization. Anal Biochem 310, 199, 2002.

64. Ricard-Blum, S., Feraud, O., Lortat-Jacob, H., Rencurosi, A., Fukai, N., Dkhissi, F., Vittet, D., Imberty, A., Olsen, B.R., and van der Rest, M. Characterization of endostatin binding to heparin and heparan sulfate by surface plasmon resonance and molecular modeling: role of divalent cations. J Biol Chem 279, 2927, 2004.

65. Uniewicz, K.A., Ori, A., Rudd, T.R., Guerrini, M., Wilkinson, M.C., Fernig, D.G., and Yates, E.A. Following protein-glycosaminoglycan polysaccharide interactions with differential scanning fluorimetry. Methods Mol Biol 836, 171, 2012.

66. Ishihara, M., Takano, R., Kanda, T., Hayashi, K., Hara, S., Kikuchi, H., and Yoshida, K. Importance of 6-O-sulfate groups of glucosamine residues in heparin for activation of FGF-1 and FGF-2. J Biochem 118, 1255, 1995.

67. Seemann, P., Schwappacher, R., Kjaer, K.W., Krakow, D., Lehmann, K., Dawson, K., Stricker, S., Pohl, J., Ploger, F., Staub, E., Nickel, J., Sebald, W., Knaus, P., and Mundlos, $\mathrm{S}$. Activating and deactivating mutations in the receptor interaction site of GDF5 cause symphalangism or brachydactyly type A2. J Clin Invest 115, 2373, 2005.

68. Murali, S., Rai, B., Dombrowski, C., Lee, J.L., Lim, Z.X., Bramono, D.S., Ling, L., Bell, T., Hinkley, S., Nathan, S.S., Hui, J.H., Wong, H.K., Nurcombe, V., and Cool, S.M. Affinity-selected heparan sulfate for bone repair. Biomaterials 34, 5594, 2013.

69. Rai, B., Chatterjea, A., Lim, Z.X., Tan, T.C., Sawyer, A.A., Hosaka, Y.Z., Murali, S., Lee, J.J., Fenwick, S.A., Hui, J.H., Nurcombe, V., and Cool, S.M. Repair of segmental ulna defects using a beta-TCP implant in combination with a heparan sulfate glycosaminoglycan variant. Acta Biomater 28, 193, 2015.

70. Murdoch, A.D., Grady, L.M., Ablett, M.P., Katopodi, T., Meadows, R.S., and Hardingham, T.E. Chondrogenic differentiation of human bone marrow stem cells in transwell cultures: generation of scaffold-free cartilage. Stem Cells 25, 2786, 2007.

71. Li, Y., Sun, C., Yates, E.A., Jiang, C., Wilkinson, M.C., and Fernig, D.G. Heparin binding preference and structures in the fibroblast growth factor family parallel their evolutionary diversification. Open Biol 6, 150275, 2016.
72. Yao, Y., and Wang, Y. ATDC5: an excellent in vitro model cell line for skeletal development. J Cell Biochem 114, 1223, 2013.

73. Shukunami, C., Ohta, Y., Sakuda, M., and Hiraki, Y. Sequential progression of the differentiation program by bone morphogenetic protein-2 in chondrogenic cell line ATDC5. Exp Cell Res 241, 1, 1998.

74. Li, L., Eun, J.S., Nepal, M., Ryu, J.H., Cho, H.K., Choi, B.Y., and Soh, Y. Isopsoralen induces differentiation of prechondrogenic ATDC5 cells via activation of MAP kinases and BMP-2 signaling pathways. Biomol Ther (Seoul) 20, 299, 2012.

75. David, G., Bai, X.M., Van der Schueren, B., Cassiman, J.J., and Van den Berghe, H. Developmental changes in heparan sulfate expression: in situ detection with mAbs. J Cell Biol 119, 961, 1992.

76. Makris, E.A., Gomoll, A.H., Malizos, K.N., Hu, J.C., and Athanasiou, K.A. Repair and tissue engineering techniques for articular cartilage. Nat Rev Rheumatol 11, 21, 2015.

77. Kafienah, W., Mistry, S., Dickinson, S.C., Sims, T.J., Learmonth, I., and Hollander, A.P. Three-dimensional cartilage tissue engineering using adult stem cells from osteoarthritis patients. Arthritis Rheum 56, 177, 2007.

78. Yoo, J.U., Barthel, T.S., Nishimura, K., Solchaga, L., Caplan, A.I., Goldberg, V.M., and Johnstone, B. The chondrogenic potential of human bone-marrow-derived mesenchymal progenitor cells. J Bone Joint Surg Am 80, 1745, 1998.

79. Feng, G., Wan, Y., Balian, G., Laurencin, C.T., and Li, X. Adenovirus-mediated expression of growth and differentiation factor-5 promotes chondrogenesis of adipose stem cells. Growth Factors 26, 132, 2008.

80. Coleman, C.M., Vaughan, E.E., Browe, D.C., Mooney, E., Howard, L., and Barry, F. Growth differentiation factor-5 enhances in vitro mesenchymal stromal cell chondrogenesis and hypertrophy. Stem Cells Dev 22, 1968, 2013.

81. Garciadiego-Cazares, D., Aguirre-Sanchez, H.I., AbarcaBuis, R.F., Kouri, J.B., Velasquillo, C., and Ibarra, C. Regulation of alpha5 and alphaV integrin expression by GDF-5 and BMP-7 in chondrocyte differentiation and osteoarthritis. PLoS One 10, e0127166, 2015.

82. Murdoch, A.D., Hardingham, T.E., Eyre, D.R., and Fernandes, R.J. The development of a mature collagen network in cartilage from human bone marrow stem cells in Transwell culture. Matrix Biol 50, 16, 2016.

83. Adeniran-Catlett, A.E., Beguin, E., Bozal, F.K., and Murthy, S.K. Suspension-based differentiation of adult mesenchymal stem cells toward chondrogenic lineage. Connect Tissue Res 57, 466, 2015.

84. Noronha-Matos, J.B., and Correia-de-Sá, P. Mesenchymal stem cells ageing: targeting the "purinome" to promote osteogenic differentiation and bone repair. J Cell Physiol 231, 1852, 2016.

85. An, B., Heo, H.-R., Lee, S., Park, J.-A., Kim, K.-S., Yang, J., and Hong, S.-H. Supplementation of growth differentiation factor-5 increases proliferation and size of chondrogenic pellets of human umbilical cord-derived perivascular stem cells. Tissue Eng Regen Med 12, 181, 2015.

86. Fernandez-Muinos, T., Recha-Sancho, L., Lopez-Chicon, P., Castells-Sala, C., Mata, A., and Semino, C.E. Bimolecular based heparin and self-assembling hydrogel for tissue engineering applications. Acta Biomater 16, 35, 2015.

87. Kim, M., Hong, B., Lee, J., Kim, S.E., Kang, S.S., Kim, Y.H., and Tae, G. Composite system of PLCL scaffold 
and heparin-based hydrogel for regeneration of partialthickness cartilage defects. Biomacromolecules 13, 2287, 2012.

88. Kim, M., Kim, S.E., Kang, S.S., Kim, Y.H., and Tae, G. The use of de-differentiated chondrocytes delivered by a heparin-based hydrogel to regenerate cartilage in partialthickness defects. Biomaterials 32, 7883, 2011.

89. Kuo, Y.C., and Tsai, Y.T. Heparin-conjugated scaffolds with pore structure of inverted colloidal crystals for cartilage regeneration. Colloids Surf B Biointerfaces 82, 616, 2011.

90. Watson, L.N., Mottershead, D.G., Dunning, K.R., Robker, R.L., Gilchrist, R.B., and Russell, D.L. Heparan sulfate proteoglycans regulate responses to oocyte paracrine signals in ovarian follicle morphogenesis. Endocrinology 153, 4544, 2012.

91. Zhang, F., Lee, K.B., and Linhardt, R.J. SPR biosensor probing the interactions between TIMP-3 and heparin/ GAGs. Biosensors (Basel) 5, 500, 2015.

92. Peysselon, F., and Ricard-Blum, S. Heparin-protein interactions: from affinity and kinetics to biological roles. Application to an interaction network regulating angiogenesis. Matrix Biol 35, 73, 2014.

93. Jiao, X., Billings, P.C., O'Connell, M.P., Kaplan, F.S., Shore, E.M., and Glaser, D.L. Heparan sulfate proteoglycans (HSPGs) modulate BMP2 osteogenic bioactivity in C2C12 cells. J Biol Chem 282, 1080, 2007.

94. Takada, T., Katagiri, T., Ifuku, M., Morimura, N., Kobayashi, M., Hasegawa, K., Ogamo, A., and Kamijo, R. Sulfated polysaccharides enhance the biological activities of bone morphogenetic proteins. J Biol Chem 278, 43229, 2003.

95. Kanzaki, S., Takahashi, T., Kanno, T., Ariyoshi, W., Shinmyouzu, K., Tujisawa, T., and Nishihara, T. Heparin inhibits BMP-2 osteogenic bioactivity by binding to both BMP-2 and BMP receptor. J Cell Physiol 216, 844, 2008.

96. Salek-Ardakani, S., Arrand, J.R., Shaw, D., and Mackett, M. Heparin and heparan sulfate bind interleukin-10 and modulate its activity. Blood 96, 1879, 2000.

97. Liu, Y., Deng, L.Z., Sun, H.P., Xu, J.Y., Li, Y.M., Xie, X., Zhang, L.M., and Deng, F.L. Sustained dual release of placental growth factor- 2 and bone morphogenic protein-2 from heparin-based nanocomplexes for direct osteogenesis. Int J Nanomedicine 11, 1147, 2016.

98. Recha-Sancho, L., and Semino, C.E. Heparin based selfassembling peptide scaffold reestablish chondrogenic phenotype of expanded de-differentiated human chondrocytes. J Biomed Mater Res A 104, 1694, 2016.

99. Zwingenberger, S., Langanke, R., Vater, C., Lee, G., Niederlohmann, E., Sensenschmidt, M., Jacobi, A., Bernhardt, R., Muders, M., Rammelt, S., Knaack, S., Gelinsky, M., Gunther, K.P., Goodman, S.B., and Stiehler, M. The effect of SDF-1alpha on low dose BMP-2 mediated bone regeneration by release from heparinized mineralized collagen type I matrix scaffolds in a murine critical size bone defect model. J Biomed Mater Res A 104, 2126, 2016.

100. Hirsh, J., Anand, S.S., Halperin, J.L., and Fuster, V. AHA scientific statement: guide to anticoagulant therapy: heparin: a statement for healthcare professionals from the American Heart Association. Arterioscler Thromb Vasc Biol 21, E9, 2001.

101. Shriver, Z., Capila, I., Venkataraman, G., and Sasisekharan, R. Heparin and heparan sulfate: analyzing struc- ture and microheterogeneity. Handb Exp Pharmacol 159, 2012.

102. Volpi, N., Maccari, F., Suwan, J., Linhardt, R.J. Electrophoresis for the analysis of heparin purity and quality. Electrophoresis 33, 1531, 2012.

103. Thomas, D.P., Merton, R.E., Barrowcliffe, T.W., Mulloy, B., and Johnson, E.A. Anti-factor Xa activity of heparan sulphate. Thromb Res 14, 501, 1979.

104. Gray, E., Hogwood, J., Mulloy, B. The anticoagulant and antithrombotic mechanisms of heparin. Handb Exp Pharmacol 207, 43, 2012.

105. Toida, T., Yoshida, H., Toyoda, H., Koshiishi, I., Imanari, T., Hileman, R.E., Fromm, J.R., and Linhardt, R.J. Structural differences and the presence of unsubstituted amino groups in heparan sulphates from different tissues and species. Biochem J 322 (Pt 2), 499, 1997.

106. Westling, C., and Lindahl, U. Location of N-unsubstituted glucosamine residues in heparan sulfate. J Biol Chem 277, 49247, 2002.

Address correspondence to: Victor Nurcombe, BSc, PhD Institute of Medical Biology Agency for Science, Technology and Research $(A * S T A R) 138648$

Singapore Singapore

E-mail: victor.nurcombe@imb.a-star.edu.sg

Anthony J. Day, MA, DPhil Wellcome Trust Centre for Cell-Matrix Research Division of Cell Matrix Biology and Regenerative Medicine School of Biology

Faculty of Biology Medicine and Health Manchester Academic Science Centre University of Manchester Manchester, M13 9PT United Kingdom

E-mail: anthony.day@manchester.ac.uk

Catherine L.R. Merry, BSc, PhD Stem Cell Glycobiology Group Centre for Biomolecular Sciences University of Nottingham, University Park United Kingdom $N G 7$ 2RD

E-mail: cathy.merry@ nottingham.ac.uk

Simon M. Cool, BSc, PhD Institute of Medical Biology Agency for Science, Technology and Research (A*STAR) (A*STAR) 138648 Singapore Singapore

E-mail: simon.cool@imb.a-star.edu.sg

Received: September 8, 2016

Accepted: November 17, 2016

Online Publication Date: January 6, 2017 